\title{
O Ensino de Línguas para Crianças no Contexto Educacional Brasileiro: Breves Reflexões e Possíveis Provisões ${ }^{1}$
}

\author{
(The Teaching of Children in the Brazilian Educational Context: Brief \\ Reflections and Possible Provisions)
}

\author{
Cláudia Hilsdorf RocHA \\ (IEL-Unicamp)
}

RESUMO: O objetivo deste artigo é discutir acerca do ensino de línguas estrangeiras (LE) para crianças. Respaldando-nos em princípios da teoria Sócio-cultural (Vygotsky, 1978) e do Comunicativismo (Almeida Filho, 1993, 2005), voltados para o ensino de línguas (inglês) para crianças (Cameron, 2001; Brewster, Ellis E Girard, 2002; entre outros), teceremos reflexões sobre a importância da aprendizagem de línguas na infância, sobre a relevância motivação e da qualidade das interações para um ensino cujo objetivo principal recai na formação integral do aluno, como também sobre o papel da gramática, da oralidade e da língua materna no processo. Serãa também feitas consideraçoes acerca da importância da formação (contínua) do professor atuante nesse contexto e de possivivis procedimentos no ensino em pauta, quando serãa apresentadas breves proposições orientadas pela noção bakhtiniana de gêneros.

PALAVRAS-CHAVE: ensino-aprendizagem de línguas; crianças; formação integral; gênero.

ABSTRACT: This article aims at discussing about the foreign language teaching to young learners, taking the principles of the Sociocultural Theory (Vygotksy, 1978) and of the Communicative Approach (Almeida Filho, 1993, 2005) related to Primary

\footnotetext{
1 Este artigo nasceu dos estudos realizados para o desenvolvimento de minha Dissertação de Mestrado, finalizada em 2006. Aproveito para expressar meus agradecimentos ao Prof.Dr. José Carlos Paes de Almeida Filho pelas valiosas orientações e à Capes, pelo apoio à minha pesquisa. Agradeço, também, à Prof ${ }^{a}$ Leila Barbara, pelo apoio constante e por acreditar em meu trabalho e, ainda, à Prof ${ }^{a}$ Cida Caltabiano, pela leitura cuidadosa desse artigo e por suas contribuições para a finalização do mesmo.
}

D.E.L.T.A., 23:2, 2007 (273-319) 
English teaching (Cameron, 2001; Brewster, Ellis E Girard, 2002) as a theoretical references. Considerations about the importance of language learning in childhood will be made, as well as about the role of the grammar, oral language and mother tongue in the process. Likewise, the importance of Teacher Education will be briefly approached. This work is ended with the discussion about some possible procedures in the language teaching processes followed by a brief presentation of possible guidelines based on the bakbtinian notion of discourse genres.

KEY-WORDS: language teaching and learning; young learners; global learning; genre.

\section{Introdução}

É dentro de um cenário educacional conflituoso, no qual muito ainda se discute sobre o papel da aprendizagem de uma LE (Leffa, 1998/1999) por crianças (Assis-Peterson \& Gonçalves, 2000/2001), que este estudo desenvolve seus questionamentos e promove suas investigações. Toma-se aqui como foco o processo de ensinar e aprender línguas (Inglês) nos Ciclos 1 e 2 do Ensino Fundamental, o qual, apesar do caráter facultativo, encontra-se consolidado nos Planos Curriculares das escolas particulares e em constante expansão no setor público.

Ao longo desse trabalho, será, primeiramente, problematizada a questão de se iniciar a aprendizagem de uma LE na infância, seguindo para seus objetivos em diferentes contextos de ensino e o significado da exclusão em sua ausência, principalmente no que diz respeito à escola regular pública. Serão, em seguida, abordados fatores intervenientes no processo de ensinoaprendizagem de LE para crianças (doravante LEC), tais como a relevância da qualidade das interações promovidas em sala (Vygotsky, 1998, 2001), o papel da língua materna no processo e a relação do ensino da LE com o letramento (Hall, 1995; Bialystok, 2001) da criança.

Posteriormente, pretendemos apresentar possíveis diretrizes para o ensino em foco, no que se refere, principalmente, aos procedimentos no processo de ensino-aprendizagem de LEC. Teceremos, também, sucintas reflexões a respeito das competências necessárias ao professor para que esse ensino seja bem sucedido. Finalizamos este artigo com a apresentação de considerações que articulam, brevemente, os aspectos nele abordados. 


\section{O ensino de LE nas séries iniciais do Ensino Fundamental: quanto mais cedo, melhor?}

Em uma sociedade globalizada, em que o contato com diferentes culturas $^{2}$ e línguas cada vez mais se intensifica através dos meios de comunicação e da tecnologia, entre outros, o ensino-aprendizagem de LE assume um papel fundamental. Nesse contexto, não sem controvérsias, o inglês (foco deste estudo) é hoje considerado uma língua universal ou internacional (Brito, 1999; Mckay, 2002). Desta forma, tem sido também crescente $\mathrm{o}$ interesse pelo conhecimento dessa língua estrangeira, dentre outras, em todo o mundo, sendo hoje uma forte tendência que o processo de aprendizagem se inicie cada vez mais cedo.

Estudiosos da área (Brewster, Ellis \& Girard, 2002; Cameron, 2001; Scott \& Ytreberg, 1990; Luz, 2003; dentre outros) apontam que vivenciamos hoje o ressurgimento pelo ensino de LE para crianças ${ }^{3}$ e mostram que o mesmo tem estado em constante expansão, tanto em escolas de idiomas, quanto em escolas da rede primária, em todo o mundo. Parece ser consenso entre os teóricos (Brewster, Ellis \& Girard, 2002; Bialystok, 2001; Alderson, 2006; entre tantos outros) que a pressão por um início da aprendizagem da LE na infância advém, principalmente, da idéia de que a criança aprende línguas mais facilmente que o adulto e de que, quanto mais cedo iniciarmos o processo, melhor.

A este respeito, Brown (2001: 86) afirma que o pensamento popular conceitua a criança como "um aprendiz que necessita despender menor esforço" " que um adulto, frente à aprendizagem de LE e que, portanto, possui melhores chances de sucesso em relação ao processo. É relevante mencionar que tais pressupostos remetem-nos à Hipótese do Período Crítico (Lenneberg,1967). Segundo Brewster, Ellis \& Girard (2002), o referido conceito foi também abordado e definido por Scovel (1988), como a

\footnotetext{
2 De forma sucinta, aqui entendemos cultura como "um conjunto colidente e conflituoso de práticas simbólicas ligadas a processos de formação e transformação de grupos sociais" (Cox \& Assis-Peterson, 2007: 33).

3 Buscando apoio em Phillips (2003) e adaptando conceitos utilizados pela referida autora à realidade brasileira, este estudo adota o termo crianças para referir-se aos aprendizes de LE que se encontram cursando os Ciclos 1 e 2 do Ensino Fundamental, ou seja, aprendizes entre 6/7 e 10 anos, aproximadamente.

4 Todas as traduções efetuadas neste artigo são de minha responsabilidade.
} 
noção de que a língua (estrangeira) é mais bem aprendida durante os anos iniciais da infância, sendo que, após um período de aproximadamente doze anos, todos nós teríamos dificuldades no que concerne à aprendizagem de uma nova língua.

Os mencionados autores pontuam, ainda, que um dos principais argumentos que sustentam a referida hipótese recai na pressuposta impossibilidade de o adolescente adquirir a pronúncia nativa da língua-alvo. Contudo, no tocante aos princípios teóricos da Lingüística Aplicada (LA), constatamos que o fator idade, atrelado a uma aprendizagem mais efetiva de uma LE, é um tema ainda bastante controverso.

Conforme ressaltam Nunan (1999), Assis-Peterson \& Gonçalves (2000/ 2001), Mitchell \& Myles (2002), dentre outros, a facilidade inata da criança para aprender outras línguas é uma hipótese sobre a qual resultados de estudos empíricos estão longe de convergir. Neste sentido, Brewster, Ellis \& Girard (2002: 21) enfatizam que, "por si só”, o início da aprendizagem de línguas na infância "não pode ser, automaticamente, considerado uma vantagem". Devemos manter em mente que muitos outros fatores, dentre eles, confiança, motivação, auto-estima e personalidade, influenciam decisivamente no processo de ensino-aprendizagem de LE.

Ao abordar a questão, Mckay (2006) pontua que devemos estar atentos aos variados programas por meio dos quais o ensino de LEC pode concretizar-se, que divergem entre si devido, principalmente, às diferenças de carga horária e objetivos estabelecidos. Nessa perspectiva, Johnstone (1994) assevera que questões relacionadas ao melhor período para o início da aprendizagem de uma nova língua, bem como acerca da certeza dos benefícios de um início na infância, não têm como ser respondidas apropriadamente, sem que tenhamos um contexto específico em foco.

Corroborando o pensamento de Moon (2001), Mckay (2006) prossegue enfatizando que os resultados da aprendizagem de línguas por crianças dependem substancialmente de diversos fatores tais como o tempo de exposição à língua-alvo, a qualidade e a variedade dessa exposição, a adequação dos objetivos ao contexto de ensino, como também a proficiência (Scaramucci, 2000), as habilidades e conhecimentos do professor em relação aos modos como a criança pensa e aprende línguas (Wood, 1998). 
Conforme assevera Falluh (1978), a polêmica discussão sobre a melhor idade para se aprender uma LE há muito vem ocorrendo entre estudiosos da linguagem, educadores, psicólogos, entre outros profissionais inseridos nessa área. A autora aponta para o envolvimento da UNESCO 5 que, sensibilizada pela relevância da questão, decidiu efetuar pesquisas e promover encontros sobre o assunto, através da atuação de seu Instituto de Educação, localizado em Hamburgo. Brewster, Ellis \& Girard (2002) mencionam a importância desses encontros como um dos marcos do interesse pelo ensino de inglês para crianças no mundo. A importância atribuída a esse ensino culmina com o ano de 2003/2004 sendo nomeado pelo Conselho Britânico como "Ano do Aprendiz Criança" (Year of the Young Learner, originalmente). Os objetivos principais de tal designação foram, conforme Ellis (2004), promover o ensino de LEC no mundo, divulgar melhores práticas e compartilhar conhecimentos na área.

Ao considerarmos os resultados dos encontros promovidos pela UNES$\mathrm{CO}$ e demais conferências e relatórios internacionais voltados para questões sobre o ensino-aprendizagem de línguas na infância, em contextos formais de ensino, podemos concluir, apoiados em Brewster, Ellis \& Girard (2002), que os mesmos culminaram em alguns pontos considerados, hoje, cruciais para que esse ensino seja bem sucedido. Entre outros, podemos citar a importância de o processo estar voltado para os interesses do aluno, o fato de não tomarmos o desenvolvimento das habilidades lingüísticas como foco único do processo e a necessidade de entendermos esse ensino como capaz de proporcionar melhor embasamento para uma aprendizagem efetiva da LE em séries posteriores.

A aparente ineficiência do ensino de línguas nas escolas regulares em nosso país, em especial as do setor público, conforme pontuam Grigoletto (2000), Walker (2003), Oliveira (2003), entre outros, assim como limitações típicas desse contexto, dentre elas, a grande quantidade de alunos por sala, o número restrito de horas semanais destinadas a esse ensino e o aparente despreparo do professor, fazem com que o valor e o propósito da aprendizagem de LE nas séries iniciais do Ensino Fundamental brasileiro sejam temas bastante conflituosos. Nessa perspectiva, muitos teóricos,

5 Informações mais detalhadas sobre os encontros mencionados podem ser encontradas no trabalho da citada autora (Falluh, 1978). 
dentre eles Assis-Peterson \& Gonçalves (2000/2001), colocam-se favoráveis ao início do ensino de línguas a partir da $5^{\text {a }}$ série, somente.

Ao discorrer sobre tal questão, Assis-Peterson \& Gonçalves (2000/ 2001: 23) enfatizam a necessidade de que reformas ocorram no setor público, a fim de que este possa "oferecer um ensino de qualidade" e defendem que, uma vez "mantidas as condições ideais", o período de estudo entre a $5^{\text {a }}$ série do Ensino Fundamental e o último ano do Ensino Médio parece ser suficiente para que os alunos adquiram "o grau de fluência desejado". Contudo, conforme ressaltam as próprias autoras (Assis-Peterson \& Gonçalves, 2000/2001: 23), "o ideal de se alcançar um domínio igual ao do falante nativo deve ser questionado e examinado".

A este respeito, lembramos que o desenvolvimento de habilidades lingüísticas não deve ser o único foco do ensino de LEC. Ellis (2004) ancorase no papel formador da LE para justificar sua inclusão nas séries iniciais do ensino formal e ressalta que o principal objetivo do ensino de LE na infância deve recair sobre o desenvolvimento da competência intercultural ${ }^{6}$ do aprendiz. Segundo a mencionada autora (2004: 15), uma língua, seja ela materna ou estrangeira, constitui-se de "crenças culturais, comportamentos e significados" e a criança, por sua vez, necessita, cada vez mais, adquirir "competência lingüística e cultural (grifo nosso) para sua realidade presente e para seu futuro”.

Nesse sentido, outros estudiosos da área, dentre eles, Moon (2000), Cameron (2001) e Phillips (2003), reforçam que esse ensino deve, além de promover o desenvolvimento lingüístico, contribuir para o crescimento intelectual, físico, emocional e sócio-cultural da criança. Desta forma, entendemos que o papel formador (Freire, 1986, 1998, 2004) do ensino da LE está intimamente relacionado ao objetivo de propiciar o desenvolvimento integral da criança (Williams \& Burden, 1997; Ellis, 2004; Brewster, Ellis \& Girard, 2002; somente para citar alguns).

É importante ressaltar os propósitos formativos do ensino de LEC envolvem a reflexão sobre o papel dessa língua-alvo em nosso país e no mun-

6 O conceito de competência intercultural aqui adotado advém de Byram e Doyé (1999) que, de forma sucinta, definem o termo como uma combinação de habilidades, atitudes e conhecimentos que, aliada às habilidades de comparação e reflexão, permite o conhecimento das diferenças culturais e amplia a visão de mundo do aprendiz. 
do e suas implicações para a sala de aula. Segundo Rajagopalan (2005:37), precisamos analisar se não estamos "repassando valores culturais contrários ao interesse nacional dos aprendizes" por meio de nosso ensino. Apoiados no mencionado autor, entendemos que o ensino-aprendizagem de LEC deve, assim, ocorrer calcado em fins emancipatórios, ampliando a visão de mundo do aluno, sem desconsiderarmos, contudo, seus próprios interesses ou desqualificarmos seus valores e constituição cultural.

De acordo com Ellis (2004), tais objetivos no ensino de LEC envolvem, dentre outros aspectos, o desenvolvimento da consciência metacognitiva do aprendiz. Brewster, Ellis \& Girard (2002: 53), por sua vez, apoiados na noção de "aprender-a-aprender" de Bruner (1986), abordam o referido conceito e o definem como "o conhecimento e a conscientização que um aprendiz tem de seu próprio processo de aprendizagem”, o que, segundo os autores citados, inclui a reflexão acerca de sua identidade lingüística e cultural. Desta forma, distante de validar o ensino como instrumento de manutenção de uma sociedade constituída por relações de extrema desigualdade, em que somos levados a acreditar que aquisição do conhecimento por si só garante emancipação, conforme pontua Duarte (2003: 5) em sua crítica às "pedagogias do aprender a aprender", o conceito de consciência metacognitiva aqui abordado envolve a reflexão crítica (Freire, 1998, 2004; Smith, 1992) sobre as relações lingüísticas e culturais mantidas pela e na linguagem.

Sobre esta questão, Ellis (2004) acrescenta que, além do desenvolvimento da consciência lingüística e cultural, o desenvolvimento da consciência metacognitiva envolve o trabalho com a auto-consciência do aprendiz, com o objetivo de que ele transcenda sua etnocentricidade. Ainda segundo a mencionada autora, tal processo envolve, também, o fortalecimento da compreensão de um mundo plural e da necessidade da paz mundial, o incentivo à curiosidade e à motivação da criança, visando à construção de atitudes positivas frente às diferenças.

Deste modo, parece-nos inadequado abordar a relevância do ensino de LE de $1^{\mathrm{a}}$ a $4^{\mathrm{a}}$ séries, tomando como referência apenas o desenvolvimento das habilidades lingüísticas e da fluência que se almeja adquirir através do mesmo, ou seja, orientando-nos meramente por objetivos instrumentais para a aprendizagem da nova língua. Nessa perspectiva, defendemos o pressuposto de que a cultura, pensada como "conjunto colidente e confli- 
tuoso de práticas simbólicas ligadas a processos de formação e transformação de grupos sociais" (Cox \& Assis-Peterson, 2007: 33), é central para o processo de ensino-aprendizagem em questão e que a interculturalidade ${ }^{7}$ revela-se como o elemento propulsor do crescimento lingüístico, intelectual, físico, emocional e sócio-cultural do aprendiz-criança.

Ao abordarmos a importância atribuída ao ensino de LEC no contexto educacional brasileiro, é interessante mencionar que, segundo Amaral (2001), muito se questionou a respeito da necessidade e da viabilidade de se ensinar LE para as crianças das séries inicias do Ensino Fundamental durante o I Encontro Nacional sobre Política de Ensino de Língua Estrangeira, realizado em Florianópolis no ano de 1996, sem que se chegasse a um consenso. Já em 2000, ano em que se realizou o II Encontro em Pelotas, os benefícios desse ensino sobrepuseram-se aos possíveis percalços de sua implantação, sendo uma das proposições estabelecidas, a de que o estudo da língua estrangeira fosse gradualmente estendido às séries iniciais do Ensino Fundamental. Esta nos parece uma decisão acertada, mediante a contribuição que a aprendizagem da LE pode oferecer para a formação global da criança, conforme já explicitado.

Devemos também salientar que, apesar de não compulsório, o ensino de línguas é parte integrante da Matriz Curricular de escolas particulares, desde o Ensino Infantil até o Médio, o que nos impede de abordar sua ausência nos ciclos iniciais do Ensino Fundamental Público, sem tocar na questão da exclusão social (Boneti, 1997) vivenciada pelos alunos das classes menos favorecidas, em relação a esse ensino. Alem disso, é pertinente mencionar, que a inclusão facultativa do ensino de LE nos ciclos iniciais do Ensino Fundamental resulta na inexistência, até o momento, de parâmetros oficiais específicos para o mesmo. Tal fato compromete o processo de ensino-aprendizagem de línguas para crianças de $1^{\mathrm{a}}$ a $4^{\mathrm{a}}$ séries, o qual vem sendo desenvolvido em inúmeras escolas públicas brasileiras, apesar de sua não obrigatoriedade. A ausência de diretrizes norteadoras específicas para o ensino de LE nos Ciclos 1 e 2 do Ensino Fundamental compromete-o, visto que objetivos claros e diretrizes bem embasadas são condições es-

\footnotetext{
7 Entendemos o conceito de interculturalidade conforme Maher (2007: 89), a qual não faz distinção entre inter e transculturalidade, na medida em que ambos os termos, para a mencionada autora, "podem - ou não- implicar interpenetração de culturas" diversas, a depender de como são concebidos.
} 
senciais, apesar de não serem as únicas, para que o mesmo seja bem sucedido (Cameron, 2001, 2003; Johnstone, 1994, 2002; entre outros).

Ressaltamos que, independentemente das limitações típicas do ensino de LE em escolas regulares, sejam elas públicas ou particulares, defendemos a existência do mesmo desde o início da aprendizagem formal e a necessidade que o ensino em questão seja alvo de intensas investigações científicas, a fim de que possamos garantir o papel formador da LE nesse contexto e preservar o direito do cidadão de aprender línguas na escola, efetivamente. Devemos ter consciência, entretanto, que há muitas variáveis a serem estudadas e pesquisadas com mais profundidade, no que se refere ao processo de ensino-aprendizagem de LEC, visando a preservar seu papel na formação integral da criança.

Entre muitos fatores, devemos atentar para a formação do professor e para a importância do desenvolvimento, por meio de cursos de formação (contínua), das competências desejáveis para que este profissional atue efetivamente no contexto em foco (Cameron, 2001; Phillips, 2003). É igualmente necessário voltarmos nossa atenção para o processo de transição entre o Fundamental I e II, para a qualidade das interações promovidas em sala (Vygotsky, 1978; Fabrício, 1999; dentre outros), para as formas de avaliação (Cameron, 2001; Iannou-Georgiou \& Pavlou, 2003; Mckay, 2006; entre outros), bem como para a proposição de objetivos claros e coerentes para esse ensino, em diferentes contextos (Johnstone, 1994, 2002; entre outros). Em suma, é essencial que se invistam tempo e recursos em pesquisas, planejamento, formação de profissionais e preparação de materiais adequados, a fim de que se consolidem as chances de sucesso na área de ensino-aprendizagem de LEC, no que concerne, principalmente, ao ensino regular público.

Diante das questões apresentadas, argumentamos que não podemos recuar diante de limitações e dificuldades. Ao invés disso, devemos lutar para se fazer cumprir o propósito da educação: formar cidadãos críticos, responsáveis, conscientes de suas ações e do mundo que os cerca, como também, capazes de atuar, satisfatoriamente, na sociedade em que vivem, em busca de seus interesses e de seu crescimento pessoal e profissional. Assim sendo, quanto mais cedo o fizermos, de maneira coerente e efetiva, melhor. 


\section{O professor de LEC e as principais diferenças entre o aprendiz adulto e a criança}

De acordo com Brown (2001) a diferença primária entre o aprendiz adulto e a criança recai no foco de atenção de ambos. $\mathrm{O}$ foco de atenção da criança é espontâneo e periférico, enquanto o adulto consegue conscientemente focar sua atenção nas formas da língua. É por esta razão, principalmente, ressalta o referido autor, que se acredita que a criança não coloca, necessariamente, tanto esforço quanto o adulto para conseguir aprender línguas.

Brown (2001) prossegue enfatizando, no entanto, que o adulto é mais bem sucedido que a criança em muitos aspectos, podendo-se citar a maior capacidade do mesmo em reter informações, em utilizar processos dedutivos e abstratos e em lidar com regras e conceitos abstratos. Para o mencionado autor, o contexto de instrução em uma sala de aula pode impor algumas dificuldades para a criança envolvida no processo de aprendizagem de uma nova língua. O mesmo, segundo o referido teórico, não acontece, necessariamente, com o adulto, o qual possui uma capacidade maior de concentração, adapta-se melhor a atividades descontextualizadas e apresenta uma necessidade menor de variação de atividades. Por outro lado, é interessante ressaltar que a criança é, geralmente, espontânea, curiosa e desinibida (Ellis, 2004), o que a favorece no que se refere à aprendizagem de uma LE.

Faz-se necessário mencionar que, embora as crianças compartilhem características no que diz respeito ao seu perfil como aprendiz de uma nova língua, elas não apresentam uma maneira uniforme de aprendê-las. A este respeito, Moon (2000: 10) salienta que são diversas e variadas as formas pelas quais as crianças podem aprender uma língua-alvo, sendo restrita a visão de que as mesmas aprendem somente "repetindo, imitando ou traduzindo" e, acrescentamos, brincando ou cantando despropositadamente.

Convergindo com o pensamento de Cameron (2001), Brown (2001) conclui que ensinar línguas para crianças de modo efetivo transcende a mera seleção de um conjunto de atividades a serem desenvolvidas durante a aula. O processo requer, por parte do professor, o desenvolvimento de habilidades e conhecimentos específicos, que diferem daqueles necessários para ensinar o adulto. Dentre os pontos fundamentais a serem trabalhados 
ao longo do processo de ensino-aprendizagem de LEC, os autores mencionados citam a importância de vários fatores, tais como, do desenvolvimento intelectual da criança, da adequação do processo ao seu foco de atenção (geralmente curto), do estímulo a todos os sentidos da mesma durante o processo, do respeito aos fatores afetivos no ensino e, finalmente, do uso autêntico e significativo da linguagem.

Brewster, Ellis \& Girard (2002), por sua vez, consideram os objetivos ou necessidades instrumentais como um dos principais aspectos que diferenciam a aprendizagem de línguas na infância da aprendizagem em fase adulta. Para os referidos autores, quando adultos, nós sempre temos um objetivo em mente quando decidimos aprender uma nova língua, seja ele voltado para a empregabilidade (Rosa, 2003) ou para qualquer outro fim. As crianças, entretanto, não decidem por si só a respeito de suas vidas e têm, ainda, muito a aprender em sua própria língua, fator este que afere ao ensino de LEC o caráter formador, já especificado.

Segundo os citados autores, no que concerne às principais diferenças entre os aprendizes mais velhos e as crianças, podemos, ainda, mencionar que as mesmas possuem muita energia física, apresentam uma gama ampla de necessidades emocionais, são facilmente instigadas emocionalmente e apresentam-se, geralmente, entusiasmadas perante o aprendizado da língua-alvo. Nesse sentido, devemos também ter em mente que as crianças tendem a se preocupar com seus próprios interesses e seu próprio mundo, sendo capazes de se concentrar por um período razoável de tempo se estiverem genuinamente interessadas, conforme acentua Cameron (2001). Contudo, é pertinente pontuar que elas tendem a se cansar facilmente, perdendo, conseqüentemente, o interesse e a atenção, rapidamente. É importante ressaltar, também, que a criança, ao ingressar no ensino formal, encontra-se no início de seu desenvolvimento conceitual e de sua alfabetização em língua materna (doravante LM), o que implica a necessidade de buscarmos maneiras efetivas de trabalharmos o processo de letramento ${ }^{8}$ (Hall, 1995; Bialystok, 2001, entre outros) em LE.

\footnotetext{
8 O termo letramento está aqui embasado, principalmente, nas concepções de Hall (1995: 244), que o concebe como "experiência social". Desta forma, o mencionado conceito relaciona-se à capacidade de ler e escrever, intrinsecamente ligada a fatores sócio-culturais, na mediada em que, dentre outros fatores, está relacionado ao desenvolvimento de habilidades que capacitem o aprendiz a atuar em práticas sociais que envolvam a linguagem escrita.
} 
Dentro dessa perspectiva, Cameron (2001) ressalta a importância de se maximizar o potencial de cada procedimento no ensino de LEC. Ao defender uma abordagem centrada no processo (grifo nosso) de ensinar e aprender, a autora aponta para a necessidade de se promover um ensino embasado em constantes e crescentes desafios para a criança. Atividades cujo principal objetivo recai na mera diversão são por ela criticadas, na medida em que desperdiçam o potencial de aprendizagem do aprendiz.

Corroboramos, neste trabalho, o pensamento de Baker (1993), que ressalta ser a questão principal no processo de ensino-aprendizagem de L2 ou LE, quem aprende o quanto de qual língua sob quais condições e, acrescentamos, como e para quê o fazem. Isto posto, enfatizamos que são muitos os fatores que influenciam o sucesso ou insucesso da aprendizagem de uma nova língua na infância. Nesse sentido, dentre muitos aspectos importantes, Cameron (2001) assevera que um ensino efetivo de línguas para crianças deve respaldar-se em princípios e pressupostos teóricos que iluminem a prática do professor que atua nesse contexto.

Caminhando na mesma direção, Phillips (2003) refere-se à formação do professor de LEC como um fator de extrema importância no processo e enfatiza que os profissionais envolvidos com LEC necessitam desenvolver habilidades específicas para desempenhar adequadamente seu papel. Cameron (2003) converge com esta idéia e explicita que, além de possuir conhecimento da língua que ensina, ou seja, ser um falante competente lingüística e sócio-culturalmente na língua-alvo, o professor precisa estar capacitado a iniciar o processo de letramento da criança na LE, ter conhecimentos relacionados à como a criança se desenvolve, pensa e aprende línguas (Wood, 1998), bem como conhecer os fatores e aspectos que a motivam (Gardner, 1985; Williams \& Burden, 1997).

Autores como Rixon (1995) e Phillips (2003) chamam nossa atenção para o fato de não contarmos com um grande número de professores capacitados a atuar satisfatoriamente no ensino de LEC em escolas primárias. No que se refere às competências e saberes necessários ao professor atuante no contexto de ensino de LEC, podemos tomar como referencial os estudos desenvolvidos por Almeida Filho (1993, 1999) e Basso (2001), os quais citam, além da competência comunicativa (Canale \& Swain, 1980), as competências teórica, aplicada e profissional, como desejáveis para o professor de línguas. O conceito de competência é aqui sucintamente concebido como 
"uma capacidade de mobilizar diversos recursos cognitivos (saberes) para enfrentar um tipo de situação” (Perrenoud: 2000:15).

Desse modo, ressaltamos que o sucesso do ensino de LEC recai, dentre outros inúmeros fatores, na formação (contínua) do professor e na relevância da reflexão crítica (Smith, 1992) como parte integrante desse processo. Nesse sentido, é pertinente salientar que a importância atribuída à educação do professor de línguas, através da prática reflexiva (Schon, 1983, 1987; Zeichner, 1993) e crítica (Kemmis, 1987; Smith, 1992; Kincheloe, 1997), tem sido fortemente defendida no contexto educacional brasileiro nas últimas décadas, por autores como Almeida Filho (1993; 1999), Moita Lopes (1996), Celani (1997; 2003), Gimenez (2002, 2003); Barbara \& Ramos (2003), Magalhães (2004), Vieira- Abrahão (2004), dentre outros.

Julgamos importante asseverar que, em se tratando de traçar o perfil ideal do professor de LEC, é necessário que mais estudos sejam desenvolvidos, visando a aprofundar nossos conhecimentos a esse respeito. Cameron (2001: 01) explicita que "precisamos desempacotar as generalizações" sobre o ensino de LEC, a fim de realmente descobrirmos como se constitui o processo de aprendizagem de uma nova língua pela criança.

Tal acepção nos leva a reconhecer, portanto, que, se há, ainda, muito a ser investigado a esse respeito, há, também, muito a ser estudado acerca das competências e conhecimentos necessários para o professor atuante nesse contexto de ensino. Entendemos, então, que cabe a nós, profissionais da linguagem e educadores, buscarmos ir sempre mais além, no que diz respeito aos princípios norteadores do ensino de línguas na infância, bem como no que concerne aos conhecimentos do professor atuante nesta área, visando à construção e desenvolvimento de um processo de ensino cujas condições sejam, cada vez mais, favoráveis à aquisição/aprendizagem de LE pelo aprendiz-criança.

\section{Interações e ações no ensino de línguas para crianças}

Rejeitando a concepção de que ensinar para crianças seja uma tarefa simples, Cameron (2001) refuta a pressuposição de que as crianças aprendem somente uma linguagem simples, destituída de qualquer complexidade, e que o ensino de LE na infância deva ser apenas divertido. A citada 
autora ressalta que o sucesso do ensino-aprendizagem de línguas depende, em grande parte, do tipo e da qualidade de interação proporcionada ao longo do processo e defende o desenvolvimento de atividades que maximizem a aprendizagem da língua-alvo.

A construção de interações (mais) significativas (Vygotsky, 1984/1998, 2001; Fabrício, 1999; Barbirato, 2005; Moura, 2005; dentre outros) no ensino de LEC (Luz, 2003; entre outros) reforça a necessidade de investigarmos fatores relacionados à afetividade, à motivação e à auto-estima do aprendiz-criança, conforme já pontuado, como também acerca do papel da oralidade (Cameron, 2001, 2003) e da LM como instrumentos de mediação no ensino-aprendizagem de uma nova língua (Vygotsky, 1984/1998, 2001; Silva, 1997; Szundy, 2002, 2005; entre outros). São igualmente relevantes trabalhos sobre as maneiras de se abordar, mais efetiva e integradamente, as habilidades (fala, escuta, leitura e escrita), o vocabulário e a gramática no referido processo (Cameron, 2001, 2003). Isto posto, passaremos a discutir tais questões nas partes que seguem.

Toma-se como premissa neste trabalho que ensinar LE nos Ciclos 1 e 2 do Ensino Fundamental brasileiro é, pro meio do trabalho com a interculturalidade, buscar auxiliar a criança a construir um caminho que a ajude a ampliar o conhecimento de si própria e do mundo em que vive, fortalecendo-a com uma visão positiva e crítica das diferenças, a integrá-la no mundo globalizado da tecnologia e da informação, a fim de fortalecer sua auto-estima e identidade, capacitando-a a agir, a comunicar em LE na sociedade plurilíngüe e pluricultural em que está inserida, respeitando-se seus valores e assegurando-lhe igualdade de oportunidade, também no que se refere ao direito a esse ensino.

Atrelando tais pressupostos à relevância de compreendermos mais profundamente como a criança desenvolve seu pensamento e quais as possíveis implicações desse processo para a aprendizagem de uma nova língua, tomamos como referencial os estudos de Vygotsky (1984/1998, 2001) e Bruner (1986). A visão, apresentada pelos citados autores, do conhecimento como algo construído ativamente através da interação, converge com a argumentação de Vale \& Feunteun (1995: 28) de que as crianças aprendem melhor quando elas são responsáveis pelo seu trabalho, ou seja, "quando elas têm a oportunidade de experienciar por elas próprias". 
De acordo com Brewster (1995) e Cameron (2001), Vygotsky e Bruner colocam uma ênfase maior que Piaget (1972) no papel da linguagem, da comunicação e da instrução no desenvolvimento da criança. Vygotsky $(1984 / 1998,2001)$ assevera que os processos mentais superiores (nossa capacidade de planejar, avaliar, memorizar e raciocinar) são culturalmente formados através da interação social, o que corrobora a importância atribuída à dimensão cultural (Moita Lopes, 2005; Cox \& Assis-Peterson, 2007) no processo de ensino-aprendizagem de LEC (Gill \& Canková, 2003; Ellis, 2004; entre outros).

Na perspectiva da teoria Sócio-cultural (Vygotsky 1984/1998, 2001), a construção do conhecimento é mediada (Lantolf, 2000a) por instrumentos ou símbolos, dentre os quais a linguagem revela-se como o principal. Cameron (2001) assevera que o adulto medeia o mundo para torná-lo mais acessível à criança, o que deve também ocorrer na sala de aula de línguas. A noção de mediação deu origem à ZDP (zona de desenvolvimento proximal) ${ }^{9}$, conceito este de fundamental importância no ensino de LEC, no tocante às interações construídas no processo. Isto porque, conforme pontuam Williams \& Burden (1997), sob a luz de princípios vygotskianos, para que a aprendizagem ocorra, é necessário que as interações produzidas na ZDP sejam significativas.

Cameron (2001) corrobora o pensamento de Vygotsky (1984/1998, 2001) de que a interação exerce um impacto decisivo (facilitador ou impedidor, segundo Fabrício, 1999) na aprendizagem e assevera que uma nova língua deve ser primeiramente usada de forma significativa pelo professor e pelos alunos, para que a mesma possa, posteriormente, ser transformada e internalizada pela criança.

Assim como para Vygotsky (1984/1998, 2001), Bruner (1986) considera a linguagem como o instrumento mais importante de crescimento cognitivo. O referido autor faz uso do termo scaffolding ${ }^{10}$ (ou andaime, em

9 Vygotsky (1984/1998) define o conceito como a distância entre o nível de desenvolvimento real, o qual é definido pela capacidade de resolução de problemas sem ajuda de um par mais capaz, e o nível de desenvolvimento potencial, determinado pela capacidade de resolução de problemas mediante auxílio.

10 Wood, Bruner \& Ross (1976) deram origem ao conceito de scaffolding, o qual, de forma breve, diz respeito ao processo de cooperação entre pares que possibilita a um indivíduo resolver problemas que, no momento, não teria condições de solucionar sem ajuda. 
português). Quando relacionado ao ensino de LEC, o mencionado conceito indica a possibilidade de o professor auxiliar a criança a ser mais autônoma (Paiva, 2005), no que concerne à aprendizagem da língua-alvo, o que nos leva à relacioná-lo à idéia de apoio ou suporte.

Cameron (2001) apoia-se nas concepções de Wood (1998) e enfatiza que o bom suporte no processo de ensino-aprendizagem de LE é aquele que se ajusta às necessidades do aprendiz, permitindo que o mesmo tornese mais competente. Wood (1998) ressalta que o adulto pode oferecer suporte à aprendizagem da criança de várias maneiras, dentre elas, chamando a atenção para o que é mais relevante, adotando estratégias apropriadas, tais como oferecer explicações claras e encorajar a prática na língua-alvo, como também procurando relembrar a criança a respeito das tarefas a serem desenvolvidas e de seus objetivos.

Bruner (1986), por sua vez, valorizou o desenvolvimento da metacognição da criança no processo educativo, enfatizando a importância do aprender-a aprender, conforme já citado. Outra implicação prática das idéias de Bruner para o ensino de LEC ressaltada por Cameron (2001:9), é a noção desenvolvida pelo autor da relevância das "rotinas" para a criança. Segundo a autora citada, o conceito da rotina na aula de línguas pode criar um elo de equilíbrio entre a segurança do hábito e a excitação proveniente do novo, sendo esse ambiente propício para o crescimento, facilmente relacionado à ZDP. Corroboramos o pensamento de Cameron (2001) ressaltando que as rotinas favorecem que repetições (significativas) ocorram, fator este considerável apropriado para o desenvolvimento da aprendizagem pela criança. A referida autora (2001: 16) enfatiza que a importância das rotinas e sua relação com o scaffolding trazem para o ensino de LE a relevância de se modelar (modelling), através de práticas significativas, o uso da linguagem trabalhada no processo.

Por sua vez, Williams \& Burden (1997) destacam a importância atribuída por Bruner (1960) de encorajar o aprendiz a fazer adivinhações sobre o funcionamento da língua-alvo e a desenvolver seu pensamento intuitivo. Para o autor isto faz crescer no aluno a curiosidade, bem como sua autoconfiança, na medida em que o encoraja a correr riscos e a aprender, também pro meio de seus erros. Recontextualizar as idéias de Bruner (1960, 1986) no processo de ensino-aprendizagem de LEC significa, entre outras coisas, considerar que o ensino bem sucedido depende do equilíbrio entre 
ensinar os aspectos considerados relevantes em relação à língua-alvo e o incentivo a uma participação ativa e mais autônoma do aprendiz.

Williams \& Burden (1997: 26) destacam Bruner como um pensador nato e pontuam que o referido autor estendeu aspectos da teoria piagetiana ao sugerir três modos distintos de pensamento, que descrevem como as crianças atribuem sentido às suas experiências: o enativo, o icônico e o simbólico. ${ }^{11} \mathrm{O}$ primeiro nível envolve as ações e indica, portanto, que a aprendizagem (de uma nova-língua) ocorre através da manipulação de objetos concretos. No segundo nível, a aprendizagem acontece por meio do reconhecimento de imagens visuais distanciadas do objeto real, as quais são reconhecidas pelo que representam do objeto ou são, às vezes, criadas independentemente. No terceiro nível, a aprendizagem relaciona-se ao uso de símbolos, os quais são manipulados em lugar de objetos ou imagens mentais.

Ao se contrapor às fases estabelecidas por Piaget ${ }^{12}$, no que concerne ao desenvolvimento da criança, Bruner $(1960,1986)$ assevera que tais níveis não se desenvolvem em seqüência linear, mas que geralmente encontram-se sobrepostos, entrelaçados. Fazendo nossas as palavras de Williams \& Burden (1997), ressaltamos que, ao relacionarmos esses níveis ao processo de ensino-aprendizagem de LEC, podemos enfatizar, respeitando-se o modo enativo, a importância do uso de dramatizações, de técnicas de TPR (total-physical-response ou resposta-física-total, em português) e da manipulação de objetos concretos, nas aulas de línguas para crianças. Da mesma forma, o modo icônico implica o uso de imagens, de figuras e de palavras em cores, por exemplo, enquanto o modo simbólico manifesta-se no curso da aprendizagem do aluno, na medida em que este usa a LE para expressar idéias em um contexto específico ou, ainda, faz uso de sua LM como mediadora para a aprendizagem da língua-alvo.

No que diz respeito à relação entre as interações promovidas na aula de LEC e o uso da LM, podemos asseverar, ancorados em autores como

\footnotetext{
11 Originalmente intitulados enactive, iconic e symbolic, respectivamente.

12 Piaget (1972) assevera que o desenvolvimento cognitivo acorre através de estágios comuns a todos os indivíduos, sendo os mesmos biologicamente determinado e, portanto, definidos de acordo com a idade. São quatro os estágios mencionados pelo autor: sensório-motor (do nascimento até os 2 anos), pré-operacional (2 a 7 anos), operacional concreto (7 a 11 anos) e operacional-formal ( a partir dos 11 anos).
} 
Cameron (2001), Luz (2003), entre outros, que devemos procurar respeitar os momentos em que a mesma aflora em determinadas atividades. A este respeito, entendemos que tais pressupostos encontram eco em Vygotsky (2001: 266), que enfatiza ser "a relativa maturidade da língua materna" um importante fator para o desenvolvimento da língua estrangeira.

De acordo com Bloor (1995), citado por Luz (2003), os padrões interacionais (orais) no processo de ensino-aprendizagem de LE apresentam enorme variação. Quando intensamente motivadas e envolvidas, ressalta o autor, as crianças tendem a fazer uso da LM. Ao buscar imitar o professor, o aprendiz pode, ao invés de usar a língua-alvo, também usar sua LM, ou, ainda, manter-se calado.

A este respeito, Bloor (1995) acrescenta que as formas de interação descritas devem ser vistas como naturais e típicas do processo e não devem, portanto, causar tensão. Nesse aspecto, o referido autor mostra-se alinhado ao pensamento de Cameron (2001), Moon (2000), Brown (2001), dentre outros, os quais enfatizam a necessidade de o processo de ensino-aprendizagem de LEC ocorrer em um ambiente em que o aprendiz sinta-se seguro e confortável.

No que concerne ao uso da LM no ensino de LE na infância, Brewster, Ellis \& Girard (2002) asseveram que a acepção de que a tradução é algo que deva ser evitado a todo custo está sofrendo alterações. Os autores pontuam que as interações em língua materna são, muitas vezes, passíveis de serem justificadas. Os referidos teóricos alertam, porém, para o fato de que essas interações em LM só devam ocorrer nos momentos em que elas possam, de alguma forma, maximizar o potencial de aprendizagem da línguaalvo, assumindo, desta forma, o papel de instrumentos de mediação no processo de ensino-aprendizagem. Nessa perspectiva, vários autores, tais como Moon (2000), acrescentam que, em várias situações, o uso da LM pode ser benéfico para a aprendizagem de uma nova língua na infância.

No que diz respeito à motivação, Gardner (1985) atribui importância primária ao papel da mesma no processo de aprendizagem de línguas, definindo o termo como uma combinação de elementos, dentre eles, esforço, desejo de atingir uma determinada meta e atitudes favoráveis frente a essa aprendizagem. Williams \& Burden (1997) explicitam que, sob uma perspectiva sócio-construtivista de motivação, é premissa básica que cada indivíduo seja motivado diferentemente. Ainda que a motivação seja 
influenciada por fatores sociais e contextuais, as pessoas constroem percepções individuais e, portanto, distintas, das variáveis sociais que as cercam, desenvolvendo, desta forma, disposições internas diferentes frente à aprendizagem de línguas.

Brown (2001) distingue dois tipos de motivação, a intrínseca e a extrínseca. A primeira é aquela despertada por sentimentos de competência e determinação pessoais, enquanto a segunda ocorre devido à espera de recompensas externas. Para o referido autor, privilegiar o desenvolvimento da motivação intrínseca no processo de ensino de LE parece ser adequado, uma vez que a motivação extrínseca poder vir a gerar certa atitude de dependência em relação ao ganho das referidas recompensas. Luz (2003), embasada em Khan (1995), privilegia a promoção da motivação desvinculada dos objetivos instrumentais no ensino de LEC, ao asseverar que a motivação da criança é maior quando parte de eventos gerados na própria sala de aula.

Apesar de ser clara a importância da motivação para um ensino-aprendizagem de línguas efetivo, no que diz respeito ao sucesso ou insucesso do processo, devemos considerar, além da motivação, a importância da criança sentir-se confortável e segura quando inserida em situações de aprendizagem da língua-alvo (Fukushima, 2004; entre outros). Figueira (2002) mostra em seu trabalho, a relevância da afetividade, bem como a importância de uma auto-estima elevada por parte da criança, para que a aprendizagem de LE possa ser bem sucedida.

Compartilhando a visão de Vale \& Feuntein (1995) de que o desenvolvimento das capacidades relacionais, afetivas e motivacionais da criança é essencial para a aprendizagem efetiva de línguas, Luz (2003) ressalta que no ensino de LEC a afetividade está intimamente relacionada à motivação. Ao discorrer sobre o assunto, a autora revela que, em situações em que as interações entre aluno-aluno são pouco freqüentes, o nível de ansiedade da criança é maior e sua motivação aparentemente menor. A referida autora conclui, portanto, serem os trabalhos em pares ou grupos de fundamental importância para o aumento da motivação nas aulas de LEC.

O papel do professor é também vital para que o aluno sinta-se (ou não) motivado a aprender uma nova língua. De acordo com Harmer (1991), as crianças atribuem grande importância à aprovação do professor, podendo sentir-se desmotivadas quando isso não ocorrer. Alem disso, ao profes- 
sor cabe a promoção de interações significativas, com o propósito de suscitar a motivação dos alunos por meio de práticas em que eles estejam ativamente engajados.

\section{A gramática, a oralidade e a escrita no ensino de LEC}

Segundo Cameron $(2001,2003)$, a aprendizagem de LE por crianças tem como elemento central a oralidade, o que nos leva a refletir sobre a importância da visão de linguagem que norteia o processo. Neste sentido, tomamos aqui como referência o modelo de construto de linguagem para o ensino de línguas proposto pela referida autora (Cameron, 2003: 109), o qual se embasa na visão de linguagem como discurso, sendo o mesmo, por sua vez, visto como "linguagem em uso".

Tal referencial, segundo a autora, busca transcender o ensino tradicional e fragmentado das quatro habilidades, em favor da prática natural da linguagem em situações reais de uso, princípios esses convergentes com pressupostos da Abordagem Comunicativa ou Comunicacional (Almeida Filho, 1993, 2005). Concordamos com a autora, especialmente quando a mesma argumenta ser preciso termos cuidado para que não façamos a criança enxergar a LE como um conjunto de palavras isoladas. Neste sentido, corroboramos a ênfase colocada por Cameron $(2001,2003)$ na relevância de adotarmos uma abordagem com um foco maior em unidades discursivas.

De acordo com Cameron (2001: 17), na área do ensino de línguas, tem sido comum dividir linguagem em quatro habilidades - ouvir, falar, ler e escrever - para, então, acrescentar o ensino da gramática, do vocabulário e da fonologia ao processo. A autora pontua que tal divisão reflete uma visão da linguagem como um sistema ou conjunto de habilidades e está em conflito com a proposta do ensino da língua para a comunicação (Almeida Filho, 1993; 2005). Cameron (2003: 107) acrescenta que a criança "busca o sentido em como a língua é usada na ação, na interação e com uma intenção”, ou propósito real, e não como um sistema externo, constituído de formas lingüísticas abstratas.

A autora (Cameron, 2001: 18) alinha seu pensamento a princípios da teoria proposta por Vygotsky $(1984 / 1998,2001)$ e pontua que, "para as crianças, a linguagem oral é o meio através do qual uma nova língua é 
encontrada, entendida, praticada e aprendida". Assim sendo, a oralidade deixa de ser apenas um aspecto do ensino de LEC, passando a desempenhar um papel primário no desenvolvimento da aprendizagem dessa nova língua pela criança. Cameron $(2001,2003)$ propõe um modelo alternativo para o processo de ensino-aprendizagem de LEC, o qual separa, inicialmente, as habilidades orais das habilidades relacionadas ao ler e ao escrever, conforme ilustra o quadro a seguir.

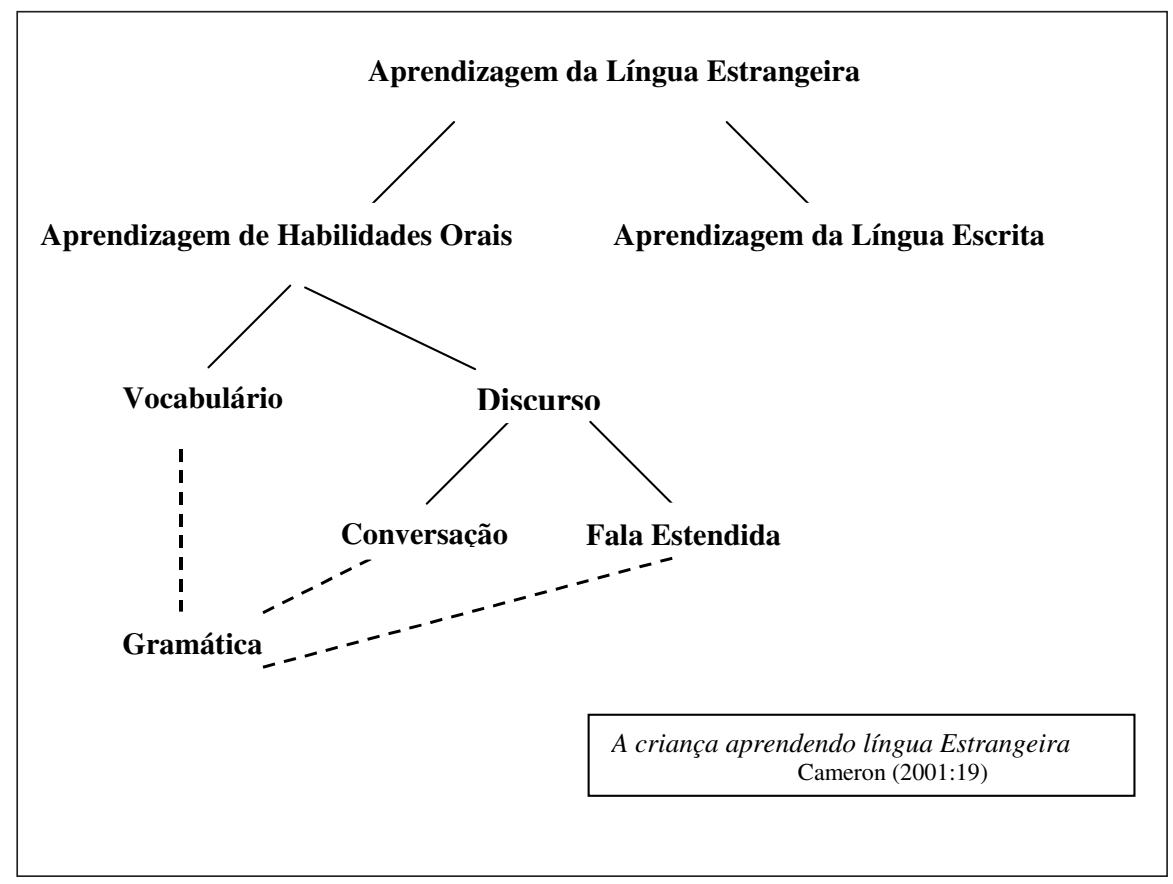

Cameron (2001: 18) segue explicitando que as habilidades orais, por sua vez, constituem-se de dois níveis, "discurso" e "vocabulário", devendo os mesmos estar sempre centrados no uso e no sentido. No nível do discurso, a linguagem freqüentemente ocorre em unidades (discursivas), as quais são geralmente mais longas que a sentença, o que nos remete à concepção bakhtiniana de enunciado. É pertinente salientar que as linhas pontilhadas no modelo proposto por Cameron $(2001,2003)$ representam, segundo a autora, a existência de padrões de regularidades da língua, os quais a criança pode desenvolver, através do trabalho com o discurso e com o vocabulário.

Conforme ilustra o quadro, contrapondo-se às "falas estendidas", que podem ser exemplificadas através das rimas, canções, histórias no ensino 
de LEC, estão as habilidades conversacionais, as quais envolvem a compreensão e o uso de enunciados na interação com o outro. As habilidades ligadas ao vocabulário, na acepção da autora, devem representar mais que o entendimento e a produção de palavras isoladas. Nas palavras de Cameron (2003: 109), o ensino de vocabulário "envolve a compreensão e o uso produtivo não apenas de palavras isoladas, mas de frases e blocos de enunciado”, os quais, ressaltamos, são instituídos de sentido ao serem sóciohistoricamente situados.

Alinhados a esta visão global e integrada do ensino de LEC, Brewster, Ellis \& Girard (2002) chamam nossa atenção para a relevância de que o ensino da pronúncia, tonicidade, ritmo e entonação igualmente transcendam a prática de sons isolados e volte-se para a produção oral em situações reais de uso, ou seja, na comunicação propositada. Ao abordarmos o ensino de vocabulário para crianças, pontuam os referidos autores, precisamos considerar o fato de as mesmas estarem vivenciando o processo de aquisição e organização de conceitos e estarem, ainda, construindo o seu vocabulário na LM. Brewster, Ellis \& Girard (2002) convergem com o pensamento de Cameron (2001:77) ao explicitar que a aprendizagem de vocabulário envolve diferentes tipos de conhecimento, dentre eles o metalingüístico. Os autores prosseguem salientando a complexidade desse ensino e ressaltando que ele se constitui de um processo contínuo, o qual se estende por toda a vida.

No que se refere à questão da quantidade de palavras a serem ensinadas, Brewster, Ellis \& Girard (2002) alegam que o número de 500 palavras por ano deve ser adaptado aos diferentes contextos de ensino-aprendizagem. Embasados em White (1988), os autores explicitam, também, alguns fatores que devem ser levados em consideração no que diz respeito ao ensino de vocabulário. Dentre eles, citamos a demonstrabilidade (facilidade de se atribuir sentido às palavras), a similaridade com a LM, a brevidade (tamanho da palavra), a regularidade de forma, a carga semântica na aprendizagem (o fato de a palavra estar relacionada a outras já conhecidas) e a relevância da palavra para a criança. Algumas técnicas apontadas pelos autores para o ensino de vocabulário incluem o uso de objetos concretos, desenhos, figuras, fotos, ilustrações, técnicas verbais (explicações, definições, entre outras) e corporais (gestos, mímica, etc), bem como o uso dos sentidos (tocar, degustar, sentir o cheiro, entre outros) e da tecnologia. 
No que se refere ao modelo proposto por Cameron (2001, 2003), ressaltamos que a gramática é nele entendida como sendo uma "gramática interna e informal", que se contrapõe a uma abordagem tradicional, "formal e externa" da mesma (Cameron, 2003: 109). Nessa perspectiva, conforme já explicitado, as atividades no ensino de LEC devem ser vistas e analisadas em termos discursivos. Podemos asseverar que a contextualização e o sentido são primários, no que se refere ao ensino da gramática em LEC. Apresentado uma visão convergente a este respeito, Brewster, Ellis \& Girard (2002) discorrem sobre diferentes maneiras de se trabalhar a mesma com crianças, as quais propiciam, através de uma abordagem indutiva, principalmente, oportunidades para o trabalho com práticas controladas em contextos significativos, como também, para o uso criativo da linguagem.

Os autores alertam, também, para a necessidade de considerarmos qual gramática ensinar, além de como ensiná-la. Para tanto, embasam-se em Lewis (1986: 9-12) para explicitar que o ensino de gramática deve envolver três categorias gramaticais: os fatos (regras que devem ser aceitas, muito mais que compreendidas), os padrões (os quais podem ser descobertos pelas crianças através do uso) e as escolhas (aspecto relacionado ao fator da escolha pessoal, no que diz respeito às estruturas gramaticais utilizadas). Em síntese, ao discorrerem sobre o ensino do vocabulário e da gramática em LEC, os teóricos apontam para a importância de o mesmo estar subordinado à construção de sentidos produzida em situações de uso significativo (e, acrescentamos, situado) da língua-alvo.

Ao nos voltarmos para a escrita e leitura em LEC, podemos pontuar que a premissa de que a oralidade é central na aprendizagem de uma nova língua pela criança tem implicações profundas para esse ensino, no que concerne à capacidade do aprendiz-criança de engajar-se em práticas letradas. Cameron (2003: 108) argumenta que não é "contrária ao ensino da escrita e da leitura", mas ressalta que a prática dessas habilidades, principalmente em LE, não é simples ou natural para a criança. Neste sentido, o pensamento da autora reitera a acepção de Vygotsky (1984/1998: 139), com relação à escrita em LM, uma vez que o mencionado autor assevera que:

"Diferentemente do ensino da linguagem falada, no qual a criança pode se desenvolver por si mesma, o ensino da linguagem escrita depende de um treinamento artificial..., o que requer atenção e esforços enormes, por parte do professor e do aluno..." 
Nesse contexto, Cameron (2003), alinhada ao pensamento de Bialystok (2001), explicita que uma análise cuidadosa das atividades envolvendo leitura e escrita deve ser feita pelo professor, a fim de certificar-se de que as oportunidades de aprendizagem não estão sofrendo restrições devido às exigências do escrever e do ler. Ressaltando a complexidade do ensino dessas habilidades, Cameron (2003) acrescenta que a criança, conforme já explicitado, encontra-se, ainda, em fase de desenvolvimento da alfabetização em sua própria língua, sendo essa aprendizagem, assim como a aprendizagem da leitura e da escrita em uma nova língua, processos lentos e gradativos, que tendem a se consolidar somente na adolescência. Desta forma, entendemos que, principalmente no que diz respeito ao ciclo $1\left(1^{\mathrm{a}}\right.$ e $2^{\mathrm{a}}$ séries), períodos em que as crianças não apresentam ainda um desempenho amadurecido frente a tais habilidades, o ensino com foco especificamente voltado à leitura e à escrita em LE deve ser precedido por uma avaliação minuciosa e cautelosa do contexto em que o processo de ensinoaprendizagem de LEC ocorre.

Vygotsky (2001: 267) cria uma analogia entre a aprendizagem de uma LE e a aprendizagem da escrita ao pontuar que "o ensino de uma língua estrangeira para o aluno escolar se funda no conhecimento da língua materna como sua base". O autor (Vygotsky, 1984/1998: 140) afirma, ainda, que a linguagem falada "é um elo intermediário" em relação à linguagem escrita. Segundo o citado autor,

“... o desenvolvimento das línguas materna e estrangeira e o desenvolvimento da linguagem escrita estão em uma interação extremamente complexa, o que, sem dúvida, sugere que pertencem à mesma classe de processos genéticos e mantêm entre si uma unidade interna" (Vygotsky, 2001: 266).

Vygotsky (2001: 267) prossegue salientando que "há todos os fundamentos para se supor que entre o desenvolvimento dos conceitos espontâneos e os científicos existem relações absolutamente análogas” às relações explicitadas entre a LM e a LE, assim como entre a linguagem oral e a escrita. Desta forma, concordamos com Cameron $(2001,2003)$ quando a autora coloca como central o papel mediador da linguagem oral para o aprendizado de uma LE pela criança.

Ao mesmo tempo, corroboramos o pensamento de Vygotsky (1984/ 1998: 139), no que se refere à ênfase colocada pelo autor no "papel fundamental que a escrita desempenha no desenvolvimento cultural da criança”. 
Assim sendo, concluímos que devemos ser cautelosos quanto às práticas que envolvem o ler e o escrever na aula de LEC, sem negligenciarmos a importância que as práticas letradas possuem, no que concerne ao desenvolvimento lingüístico, cognitivo e sócio-cultural do aprendiz.

\section{Tópicos, temas, tarefas e projetos: a dimensão inter/ transdisciplinar em LEC}

Ao discorrer sobre como as crianças aprendem LE e sobre as diferentes maneiras de se concretizar esse ensino, Holderness (1995: 18) explicita que a aprendizagem baseada em tópicos (topic-based) ou temas (theme-based) é, geralmente, bastante apreciada. Cameron (2001) define que a noção essencial do ensino orientado por temas é a de que diversas e variadas atividades estejam inter-relacionadas através do seu conteúdo. Por esta razão, esse tipo de ensino é também conhecido como ensino de conteúdo (content-based).

É pertinente, neste momento, salientar que o termo conteúdo distanciase de concepções conteudistas (gramaticalistas) e assimilativas da aprendizagem e não está relacionado, portanto, direta e unicamente a pontos gramaticais ou a aspectos formais da linguagem. Ao invés disso, os conteúdos representam os tópicos/temas através dos quais os conhecimentos serão mobilizados, visando à construção de competências no ensino de LEC.

Scott \& Ytreberg (1990: 84) pontuam que o trabalho orientado por tópicos ou temas é uma maneira "útil, prática e prazerosa" de se ensinar crianças. As autoras enfatizam que, dentre outros fatores, o conteúdo torna-se mais importante que a língua em si, os temas ajudam a acelerar o processo de aprendizagem, os tópicos despertam o interesse e sentimentos do aluno e permitem um ensino mais personalizado, possibilitando o trabalho com todas as habilidades, respeitando-se a centralidade da construção de sentidos no processo. Nessa perspectiva, podemos compreender o ensino temático como uma alternativa viável para que a aprendizagem de LEC se efetive, devido à possibilidade que o mesmo oferece de engajar a criança na construção de sentidos, através da ação propositada e colaborativa.

Quando abordamos o ensino de LEC, é interessante que façamos a distinção entre tarefas e atividades, termos esses que, conforme asseveram 
Brewster, Ellis \& Girard (2002: 49), "são frequentemente usados como se fossem sinônimos”, mas que, na verdade, expressam diferentes visões de ensino e aprendizagem. Segundo os referidos autores, as atividades têm como foco o ensino dirigido e a aprendizagem de itens específicos de linguagem ou de habilidades, preparando os alunos para executarem as tarefas, as quais privilegiam uma aprendizagem mais significativa, o que, por sua vez, reitera a relevância de a aprendizagem possuir valor real para o aluno (Williams \& Burden, 1997).

Brewster, Ellis \& Girard (2002) acrescentam que as atividades estão voltadas para a prática da linguagem (forma e significado), mas não são significativas em sua essência, na medida em que se constituem de um conjunto de operações cognitivas simples, que levam o aluno a praticar uma série de itens de linguagem ou de sub-habilidades, individualmente ou em pares. Na concepção dos citados autores, as tarefas, por sua vez, envolvem um contexto específico, além de propósitos significativos, os quais levam os alunos a usarem a linguagem com objetivos reais.

A tarefa, conforme pontuam Brewster, Ellis \& Girard (2002: 50), “encoraja os alunos a personalizarem a linguagem, buscarem seus interesses e a usarem a linguagem de uma forma independente e criativa”. Tais características tornam as tarefas, em nossa acepção, mais apropriadas que as atividades, para constituírem o ensino-aprendizagem de LEC. Nesse sentido, enfatizamos que a noção de tarefas defendida pelos autores citados converge com as definições de Nunan (1989), Prabhu (1987), Almeida Filho \& Barbirato (2000), entre outros.

Ao retornar nossa atenção ao ensino temático, é interessante ressaltar que, de acordo com Brewster, Ellis \& Girard (2002), o ensino baseado em temas, quando bem concretizado, tem o potencial de produzir um processo altamente significativo e inspirador. Neste sentido, Holderness (1995) também afirma que, quando o trabalho com temas é bem desenvolvido, as crianças têm um conteúdo interessante assegurado e um contexto motivante a ser compartilhado, o que propicia uma ênfase natural no sentido e cria um propósito genuíno para a aprendizagem de LE.

Holderness (1995) enfatiza, ainda, que nesta perspectiva de trabalho, as crianças não mais aprendem a língua pela língua. Ao invés disso, a aprendizagem de LE ocorre visando a ampliar e a estender os horizontes do aprendiz, através de um ensino calcado em uma vertente holista e inter- 
cultural. A este respeito, concordamos com as acepções de que o ensino temático tem condições de tornar a aprendizagem da língua-alvo mais significativa, uma vez que os propósitos de uso da linguagem na aula de LEC passam a ser mais reais, na medida em que têm maior ligação com o mundo da criança.

Em contrapartida, quando não muito bem articulado, Cameron (2001) acentua que o ensino baseado em temas pode trazer resultados caoticamente improdutivos. Ainda que pareça não haver consenso entre a maioria dos teóricos a este respeito, é pertinente apontar que muitos autores julgam ser o referido ensino altamente exigente. Dentre outros fatores, Cameron (2001) salienta que o ensino temático é mais complexo, no que concerne à preparação dos professores, os quais devem possuir considerável capacidade de planejamento e gerenciamento de aula, bem como um sólido conhecimento da língua-alvo, a fim de manter um nível adequado de variação e apropriação das atividades propostas e estimular o interesse do aluno. Tal pressuposto retoma a importância vital da preparação e formação adequada do professor para o sucesso da aprendizagem de LE pela criança, conforme já discutido neste trabalho.

Em busca de um ensino que faça realmente sentido para o aluno, Halliwell (1992) amplia o escopo do ensino temático ao sugerir que o ensino de LE seja relacionado a outras disciplinas do currículo, o que entendemos ser imensamente produtivo, uma vez que sustenta a formação integral do aprendiz. A interdisciplinaridade nos permite trabalhar diferentes linguagens com a criança, o que envolve a ligação entre o ensino de línguas e tecnologia, como também o trabalho com uma diversidade de expressões culturais, tais como a dança, a pintura, o teatro, a música, trabalhos manuais (Wright, 2001), entre muitas outras.

De acordo com Halliwell (1992), o trabalho interdisciplinar pode ocorrer de várias formas, dentre as quais podemos citar: o conteúdo de outras disciplinas pode ser trabalhado nas aulas de LE; o conteúdo de LE pode ser utilizado em outras disciplinas; aulas de outras disciplinas podem ser ministradas em LE. Para Cameron (2001: 184), o ensino de línguas orientado por temas, nessa perspectiva, "pode ser usado em grandes ou pequenas escalas e em uma gama variada de concentrações”. A autora pontua que excelentes experiências holistas podem ser produzidas com esse ensino, através de rigorosa atenção aos detalhes do planejamento e do gerenciamento da aula. 
A este respeito, encontramos também apoio em Brewster, Ellis \& Girard (2002: 129), os quais pontuam que lingüistas, como Van Lier (1996) e Widdowson (1978), sugerem que o ensino de LE relacionado ao currículo escolar é mais motivante que o ensino tradicional (gramaticalista) por explorar a imaginação e criatividade do aprendiz, bem como por ter um potencial maior de criar um ambiente educacional que atenda mais prontamente aos interesses e necessidades dos alunos. Eles acrescentam, ainda, que esse ensino pode possuir características transdisciplinares, na medida em que resgata a experiência de vida do aluno e viabiliza a possibilidade da criação de vínculos entre sua casa e a escola.

Além do ensino temático orientado por tarefas, entendemos que o trabalho a partir de projetos parece, também, oferecer a possibilidade da concretização de um ensino que prime pela construção de sentidos e que seja significativo para o aluno. Segundo Phillips, Burnwood \& Dunford (2001:6), os projetos no processo de ensino-aprendizagem de LEC podem ser descritos como um "exemplo singular de aprendizagem experiencial". Segundo a definição das autoras citadas, os projetos constituem-se de unidades de trabalho que têm um começo, um meio e um fim, as quais são ligadas através de atividades significativas, visando a um produto final, o qual, por sua vez, traz à criança um sentimento de realização.

Para Phillips, Burnwood \& Dunford (2001: 6), "os projetos são um veículo ideal para ensinar crianças da escola primária por inúmeras razões". Dentre elas podemos citar sua capacidade de desenvolver a independência do aprendiz, bem como de possibilitar o trabalho em classes numerosas, constituídas por alunos que apresentem diferentes necessidades e habilidades. Entre outras vantagens citadas, podemos mencionar o foco na formação integral da criança, o grau de responsabilidade que o trabalho com projetos desenvolve no aluno, o potencial dos projetos em propiciar a cooperação entre os aprendizes e o aumento do nível de envolvimento pessoal dos mesmos no processo educativo.

Se compararmos a concepção de Phillips, Burnwood \& Dunford (2001) à proposição de trabalho com projetos de Hernández (1998), podemos asseverar que, embora este proponha uma ligação mais profunda entre as disciplinas do currículo e enfatize a relevância da pesquisa na pedagogia de projetos, encontramos vários pontos convergentes entre as referidas propostas. Dentre as características marcantes do trabalho com projetos propos- 
to pelos teóricos mencionados, salientamos a importância da idéia de aprendizagem vinculada ao fazer e à resolução de problemas, da existência do tema como um fio condutor para o ensino, da relevância de uma atitude de cooperação entre os participantes, do trabalho com diferentes tipos de informação, da visão crítica frente à realidade, entre outros.

No que concerne ao ensino de LEC, consideramos que as tarefas e os projetos permitem, ainda, a integração de aspectos sócio-culturais ao processo e possibilitam, portanto, o desenvolvimento da competência intercultural (Byram \& Doyé, 1999; Ellis, 2004) do aprendiz. Neste sentido, Brewster, Ellis \& Girard (2002) salientam que, aliados às musicas, aos desenhos, às histórias e aos trabalhos manuais, o trabalho com projetos, orientado por uma abordagem intercultural, permite que as crianças façam descobertas por si próprias por meio da observação e da comparação, o que, por sua vez, propicia o desenvolvimento metacognitivo das mesmas.

\section{A Música, a História e a Brincadeira em LEC}

Neste trabalho, concebemos os jogos, as histórias e as canções infantis como gêneros (Marcuschi, 2006, entre outros). Isto decorre de nossa acepção de que tais práticas podem ser consideradas atividades sociais, que envolvem o uso da linguagem de forma culturalmente organizada e que seguem padrões convencionais, de modo interativo, processual, flexível e dinâmico.

No tocante às canções e cantigas, Brewster, Ellis \& Girard (2002: 162) asseveram que a "natureza repetitiva e rítmica" das mesmas faz delas um excelente veículo para o processo de ensino-aprendizagem de LE na infância. De forma breve, os citados autores afirmam que o uso de canções, cantigas e, também, das rimas, pode ser considerado uma fonte de recursos lingüísticos, afetivos, cognitivos e sócio-culturais, o que se alinha aos objetivos estabelecidos para o ensino em questão, já aqui explicitados.

Embasados nos citados autores, podemos ainda mencionar que as canções, cantigas e rimas são particularmente úteis, entre outros fatores, para a prática da pronúncia, tonicidade, ritmo e entonação. Conforme acentuam Brewster, Ellis \& Girard (2002), através delas, podemos desenvolver a prática integrada das habilidades e propiciar um ambiente de repetição 
natural, o que favorece o desenvolvimento da concentração, memória e coordenação na criança.

Ao utilizarmos as músicas em sala de aula de LEC, principalmente as que fazem parte da cultura popular, podemos, na medida em que recontextualizamos tais práticas para a sala de aula, motivar os alunos e encorajá-los a engajarem-se na ação de cantar na língua-alvo. Essa abordagem permite-nos abarcar questões relacionadas à identidade e à auto-estima do aluno, bem como a valores sócio-culturalmente estabelecidos, auxiliandonos, portanto, a trabalhar a interculturalidade no processo. Segundo Brewster, Ellis \& Girard (2002: 168), outra vantagem do uso das canções na aula de línguas reside no fato de elas serem extremamente "flexíveis" e de poderem, desta forma, ser usadas em diferentes momentos da aula e com diferentes propósitos. Os autores pontuam, ainda, que elas são facilmente adaptáveis e que servem, também, para trabalhar a afetividade nas aulas de LEC.

Não é segredo que as crianças apreciam dramatizações e jogos. Brewster, Ellis \& Girard (2002: 172) asseveram que tais atividades "divertem, motivam e ensinam”. Para justificar a inclusão dos jogos no ensino-aprendizagem de LEC, Lewis \& Bedson (2000: 7) pontuam que jogar é parte integrante e vital do processo de crescimento e aprendizagem, o que se alinha à concepção vygotskiana da brincadeira como instrumento mediador do desenvolvimento da criança. Nessa perspectiva, parece ser consenso entre teóricos que excluir o jogo da aula de línguas na infância significa privar a criança de uma ferramenta essencial para sua compreensão do mundo.

Cameron (2001) e Martin (1995), por sua vez, ressaltam que, através do jogo, as crianças experienciam, descobrem e interagem com o seu meio. No entanto, os autores também enfatizam que a brincadeira deva ser mais que apenas divertida, a fim de que o ensino de LE cumpra seu papel formador. Szundy (2005) caminha na mesma direção ao salientar que, quando utilizados como atividades didáticas integradas ao conteúdo proposto, os jogos contribuem significativamente para a aprendizagem de LE. A este respeito, Cardoso (1996: 83) corrobora o pensamento de Cameron (2001) e pontua que o jogo, na aula de línguas, deve maximizar a aprendizagem, ao invés de apresentar-se como "uma atividade ingênua". 
Além de gerar motivação, Lewis \& Bedson (2000) afirmam que o contexto criado pelo jogo pode fazer com que a língua-alvo torne-se extremamente útil para a criança, uma vez que ela pode ser o instrumento através do qual a interação entre os aprendizes possa vir a ocorrer. O jogo, de acordo com os autores, orienta-se pelos mesmos princípios norteadores da aprendizagem baseada em tarefas (Prabhu, 1987; Nunan, 1989; Ellis, 2003; entre outros), visto que o principal objetivo é atingir uma meta que não está diretamente relacionada a objetivos lingüísticos, exclusivamente.

Autores como Brewster, Ellis \& Girard (2002), Lewis \& Bedson (2000), entre outros, enfatizam que a competição não é pré-condição para que o jogo aconteça no ensino de LE na infância. A construção do conhecimento na língua-alvo pode ocorrer, de maneira bastante efetiva, através de jogos de caráter colaborativo ou cooperativo, nos quais pares ou grupos de alunos trabalham juntos, visando a alcançar um determinado objetivo. É importante mencionar que, além do jogo, outras atividades que propiciem o engajamento da criança em práticas sociais que lhe pareçam divertidas ou que a coloquem em uma situação de interação e cooperação entre pares, potencializando a aprendizagem, podem ser relacionadas à importância do brinquedo na Teoria Sócio-cultural (Vygotsky, 1984/1998, 2001), devido ao seu potencial de criar a ZDP.

Contudo, conforme salienta Baquero (1998), nem toda a atividade lúdica gera $\mathrm{ZDP}$, do mesmo modo que nem toda aprendizagem ou ensino o faz. Para que isso ocorra, segundo o autor, é necessário que a brincadeira cumpra as duas funções essenciais atribuídas a ela no desenvolvimento da criança. A primeira é o seu papel de exercitar, no campo imaginário, a capacidade da criança de planejar, imaginar e representar papéis do quotidiano. Sua outra função é a de explorar o caráter social do jogo, ou seja, a de promover a adequação da criança às regras sociais e culturais constitutivas dessa prática social.

Ao abordar a importância do jogo no ensino-aprendizagem de línguas, Cardoso (1996: 36), embasada em Huizinga (1990), considera o mesmo como "um fator presente em todas as situações da vida". Segundo a referida autora,

"No jogo o aluno aprende, ainda, a se organizar, desenvolve a competência estratégica de viver em sociedade, respeitando e compreendendo seus limites pessoais através da aceitação e da valorização de atitudes e modos de ser dos colegas. Aprende a esperar a sua vez através de regras internas que dirigem a atividade" (Cardoso, 1996: 36). 
Lewis \& Bedson (2000) desenvolvem seu pensamento na mesma direção ao salientarem que o elemento que diferencia o jogo das demais atividades na aula de LE é o conjunto de regras que sempre acompanha e norteia o mesmo. A este respeito, Cardoso (1996: 37) pontua que o jogo no ensino-aprendizagem de LE "consiste em uma atividade organizada" que possui, dentre outras propriedades, uma tarefa ou objetivo específico, além de um conjunto de regras. Essa atividade, conforme ressalta a autora, envolve, necessariamente, uma situação de comunicação real entre os participantes, através da linguagem escrita ou oral, que se oriente pela meta de se alcançar o objetivo estabelecido.

Para Silva (1997: 3), os jogos ou brincadeiras criam oportunidades de negociação de significado, uma vez que promovem "situações em que as crianças precisam e querem se comunicar para terem a sua participação garantida". Além do papel motivacional do jogo no processo de ensinoaprendizagem de LE na infância, Szundy (2002) acentua o potencial do lúdico na construção do conhecimento e, também, da linguagem. Silva (1997) também reconhece a importância da motivação gerada pelo jogo, porém defende que o foco principal da brincadeira deva transcender propósitos motivacionais e recair sobre seu potencial de gerar atividades de linguagem (Schneuwly, 1988).

A noção de atividades de linguagem, por sua vez, relaciona-se a princípios da teoria sócio-cultural (Vygotsky, 1984/1998, 2001), uma vez que se encontra vinculada ao conceito de atividade proposto por Leontiev (1983). Segundo o autor, a atividade pode ser descrita como uma estrutura do comportamento orientada por um propósito social, que tem sua origem em situações de comunicação e que pode, assim, ser considerada como uma interface entre o indivíduo e seu meio. Cook (1997: 228) assevera que a criança, ao vivenciar o processo de aquisição da linguagem, "passa muito tempo produzindo e recebendo jogos de linguagem".

Ressaltamos, portanto, que, em nossa acepção, o conceito de jogo aborda dois campos distintos. $\mathrm{O}$ jogo pode, primeiramente, ser entendido como prática social regida por regras e que envolve a participação de indivíduos que buscam alcançar um determinado objetivo. $\mathrm{Na}$ acepção de Abreu \& Lima (1996), podemos conceber tais práticas como jogos culturais. Em contrapartida, ao abordarmos a noção de jogo, podemos, também, referirnos aos jogos de linguagem, os quais, por sua vez, implicam a brincadeira 
com as formas composicionais da linguagem e a construção de sentidos através delas.

Nessa perspectiva, Szundy (2002: 87) busca apoio em Bruner (1975) e argumenta que é o "interjogo entre a função instrumental da linguagem e a sua estrutura gramatical que permite à criança entrar no mundo da linguagem tão rapidamente". A este respeito, Cook (1997) pontua que os jogos de linguagem, ao serem descritos como a atividade mútua entre o adulto e a criança, mostram-se essenciais para a constituição da linguagem e para seu desenvolvimento. Conseqüentemente, são, também, importantes instrumentos para a construção de conhecimento em LM e LE.

Szundy (2002: 87) prossegue salientando que os jogos de linguagem, no processo de ensino-aprendizagem de LE, "permitem a prática recorrente dos objetos lingüísticos em construção”. Cook (1997) acrescenta que os jogos de linguagem envolvem, entre outros aspectos, práticas de repetição da linguagem através de histórias, as quais as crianças apreciam ouvir repetidas vezes, bem como através de rimas e canções, que elas também saber de cor. O referido autor salienta, ainda, que os jogos de linguagem envolvem práticas específicas de construção de sentidos, através da combinação de ritmos e sons, presentes, entre outros, nas rimas e canções infantis.

É importante ressaltar, no entanto, que os jogos de linguagem encontram-se, geralmente, mais próximos aos gêneros secundários, pois envolvem práticas relacionadas a tipos mais complexos de interações. O jogo ou brincadeira entendido como atividade cultural, por sua vez, aproxima-se de práticas sociais mais simples, relacionando-se, desta forma, ao conceito de gêneros primários.

No que se refere às histórias no processo de ensino-aprendizagem de LEC, Silva (1997: 32) afirma que "contar histórias é uma forma de brincar". Segundo a autora, quando envolvidos na situação de (re)contar histórias, brincamos de ser e/ou imitar personagens, brincamos de adivinhar o que vai acontecer, e até mesmo, brincamos de contar a história. Assim, conforme acontece com o jogo, o ato de contar histórias é convencionalmente instituído em nossa sociedade, envolve regras que devem ser seguidas, promove o trabalho colaborativo e trabalha com o imaginário da criança.

Brewster, Ellis \& Girard (2002: 186) convergem com Wright (2001)e conceituam as histórias como sendo motivadoras e extremamente ricas em 
seu potencial de gerar experiência com a linguagem. Os autores descrevem as mesmas como práticas desafiadoras, além de divertidas. Wright (2001) enfatiza a capacidade que a ação de contar histórias possui, no que concerne a promover interações significativas, desenvolver a fluência oral do aprendiz e estimular as habilidades de leitura e escrita, se desejado for. Cameron (2001: 159), por outro lado, considera as histórias como sendo, basicamente, uma atividade oral, uma vez que existem para serem contadas e ouvidas. A citada autora reforça que as mesmas são também temáticas e podem ocorrer em diversos e variados momentos durante o processo de ensino de LEC.

Silva (1997) demonstra convergir com o pensamento dos autores mencionados, ao destacar as histórias como um potente instrumento para a construção do conhecimento na língua-alvo. A autora salienta a importância da LM como mediadora do processo de ensino de LEC através de histórias. A este respeito, Silva (1997:128) ressalta que as histórias permitem que a criança transfira "para a nova língua o sistema de significados que já possui na sua própria”. No tocante ao contar histórias em LEC, Brewster, Ellis \& Girard (2002) asseveram, ainda, que podemos criar, através dessa prática, um ambiente favorável para o desenvolvimento de atitudes positivas frente às diferenças sociais e culturais.

É importante ressaltar que existe uma variedade grande de atividades que podem se relacionar ao ato de cantar, brincar e contar histórias na aula de línguas, tais como, o desenho, a pintura, a colagem e outras atividades manuais, bem como atividades voltadas para o vocabulário e para a dramatização. Uma vez que as histórias contêm usos de linguagem típicos de textos poéticos e literários e um rico vocabulário, podemos também pontuar que o ato de contar histórias permite que muitos pontos sejam trabalhados no processo de ensino-aprendizagem de LE na infância, dentre os quais podemos citar a aliteração, as metáforas, a intertextualidade, a narrativa e o diálogo.

Nessa perspectiva, ressaltamos a importância da linguagem escrita, além da oral, para o desenvolvimento cultural da criança (Vygotsky, 1984/ 1998, 2001). Enfatizamos, também, a relevância do desenvolvimento dos gêneros secundários através dos primários (Bakhtin, 1979/2003) no ensino de LEC, a partir do momento considerado oportuno pelos agentes educacionais. 


\section{O ensino baseado em gêneros: uma possível diretriz para LEC}

Segundo Marcuschi (2002: 22), a comunicação verbal não tem como realizar-se senão através de algum gênero, visto que os mesmos "contribuem para ordenar e estabilizar as atividades comunicativas do dia-a-dia”. Partimos, assim, da premissa de que é através dos gêneros que organizamos nossas atividades sociais/de linguagem e que, consequentemente, materializamos as interações com o outro em situações de comunicação propositadas e situadas (Bakhtin, 1979/2003, 1929/2004).

Ao propor uma visão enunciativa ou discursiva da linguagem, Bakhtin (1929/2004) assevera que a palavra somente adquire sentido quando inserida em uma situação social de enunciação. $O$ autor aborda o conceito de gênero, especificando-os como diferentes tipos de enunciados, criados nos vários campos da atividade humana. Os "gêneros do discurso" são definidos pelo autor (Bakhtin, 1979/2003: 262) "como tipos relativamente estáveis de enunciados”, elaborados por cada esfera de utilização da língua, refletindo suas condições e finalidades específicas. Ao serem concebidos como instrumentos que fundam a comunicação, os gêneros discursivos (Rojo, 2005) representam o uso situado da linguagem e, quando relacionados ao ensino-aprendizagem de LE, podem ser entendidos como espelhos das relações entre os indivíduos no nível pedagógico, o que cria um vínculo entre as interações promovidas em sala e situações reais de comunicação.

Assim como na Teoria Sócio-cultural (Vygotsky, 1984/1998, 2001), na perspectiva dos gêneros do discurso (Bakhtin, 1979/2003), a língua é tida como atividade social, histórica e cultural. Nessa perspectiva, portanto, a natureza interativa e social da linguagem é privilegiada, ao invés do aspecto formal ou estrutural da mesma. Assim sendo, concordamos com Ticks (2005: 23) quando a autora menciona que o desenvolvimento de uma "pedagogia baseada em gênero" tem como norte a construção do processo de ensino-aprendizagem de LE, orientado pelo uso da linguagem em diferentes interações sociais, determinadas sócio-culturalmente.

Por representarem o uso funcional da linguagem e estarem estreitamente vinculados a esferas sociais de produção, os gêneros discursivos, quando usados como embasamento para o ensino de LEC, podem promo- 
ver o desenvolvimento das competências/capacidades ${ }^{13}$ necessárias, para que o aprendiz consiga engajar-se discursivamente nas práticas de uso de linguagem valorizadas no ensino de línguas em foco. Desta forma, asseveramos que, do mesmo modo que são considerados "megainstrumentos" para agir em situações de ensino-aprendizagem em LM (Schneuwly, 2004: 28), podemos também reconhecê-los como megainstrumentos para o ensino de LE na infância.

O ensino de línguas por meio de gêneros parece garantir o desenvolvimento de práticas orientadas pelo uso da linguagem em situações reais e situadas de comunicação, que se manifestem através de interações significativas e da colaboração entre pares (Vygotsky, 1984/1998, 2001), condições estas primordiais para a construção do conhecimento pela criança, conforme acentuam Cameron (2001, 2003), Brumfit (1995), dentre outros. Da mesma forma, a faceta dos gêneros de não serem caracterizados primariamente por aspectos estruturais (Rojo, 2005), permite que a gramática abordada no ensino de LEC aflore da linguagem em uso (Cameron, 2001; 2003) e tenha como referência o que as "pessoas fazem com a linguagem quando a usam" (Cameron 2001: 101), distanciando-se, deste modo, da gramática "externa ou pedagógica”, que, segundo a referida autora, consiste, basicamente, em descrições explícitas da linguagem como um sistema de regras a serem obedecidas.

No que concerne ao contexto de ensino de línguas na infância, entendemos que o conceito de gênero discursivo converge com a visão de discurso como linguagem em uso, defendida por Cameron (2001, 2003). Ressaltamos, ainda, que o ensino por meio de gêneros parece-nos apropriado para o ensino de LEC, na medida em que, ao permitir a possibilidade de a linguagem oral ser trabalhada através dos gêneros primários (Bakhtin, 1979/2003), típicos de situações de comunicação oral do quotidiano, permite-nos respeitar a importância da oralidade como instrumento de mediação da aprendizagem da LE pela criança (Cameron, 2001, 2003).

\footnotetext{
13 Segundo Cristovão (2005: 106), o uso dos conceitos de competência, capacidades, habilidades e conbecimentos depende do posicionamento teórico dos autores que utilizam os mesmos para argumentarem sobre o processo educativo. Barbosa (2001) também argumenta nessa direção e enfatiza que a noção de competência, assim como as outras terminologias - babilidade, capacidade, uso de estratégias, etc. - são complexas e podem ser, por vezes, problemáticas, porque carregam traços de perspectivas teóricas distintas. Não nos interessa, neste artigo, aprofundarmos essa discussão e, portanto, ambos os termos são, aqui, usados indistintamente.
} 
Ao reiterarmos o já discutido papel mediador da LM na aprendizagem de uma LE pela criança (Vygotsky, 1984/1998, 2001), podemos relacionar princípios vygotskianos à teoria da enunciação bakhtiniana. Do mesmo modo que os conceitos espontâneos são instrumentos para a formação dos conceitos científicos, a língua materna, já tendo sido apropriada pelo indivíduo, assume uma função mediadora essencial para a formação de conhecimentos em LE, conforme assevera Vygotsky (1984/1998, 2001).

É análoga à relação explicitada, a relação dinâmica e de contínua interdependência estabelecida entre os "gêneros primários", produzidos em circunstâncias de comunicação (oral) espontânea e os "secundários", constitutivos das situações de convívio cultural mais organizado, segundo Bakhtin (1979/2003: 253). Defendemos, portanto, o pressuposto de que o trabalho através de gêneros já apropriados pela criança em sua cultura, provavelmente primários em sua maior parte, faz deles potentes instrumentos para a construção de significados e de conhecimentos na LE.

O ensino-aprendizagem de LEC por meio dos gêneros implica, em nossa acepção, o desenvolvimento de estratégias de aprendizagem, bem como de capacidades lingüísticas, afetivas, (meta) cognitivas e sócio-culturais do aprendiz, através de práticas sociais que constituam o universo infantil. A este respeito, Dolz \& Schneuwly (1996) consideram o grupo dos gêneros que contam histórias (contos de fadas, rimas infantis, lendas, entre outros) como muito efetivo no ensino de línguas na infância. Além do contar histórias (Wright, 2001; Scaffaro, 2006; dentre outros), podemos também citar a brincadeira (Vygostky, 1984/1998, 2001) ou o jogo (Lewis \& Bedson, 2000; Szundy, 2002, 2005; Tambosi, 2006; entre outros), a dramatização (Bruner, 1986) e as músicas, como potentes instrumentos para o ensino de línguas para crianças, conforme aqui já discutido.

É importante salientar que uma prática orientada por gêneros discursivos permite-nos sustentar, no processo educativo, a relevância do brinquedo e do mundo imaginário para o desenvolvimento do aprendiz (Vygostky, 1984/1998, 2001). A este respeito, Silva (1997: 15) pontua que os jogos, as cantigas e as histórias "fazem parte da vivência das crianças" e podem, assim, ser considerados potentes geradores da ZDP no ensino-aprendizagem de LEC. Uma vez que a interação social é construída culturalmente (Vygotsky, 1984/1998, 2001), consideramos que o ensino através dos gêneros possibilita, também, condições para o desenvolvimen- 
to da competência intercultural (Byram \& Doyé, 1999), concebida, conforme já explicitado, como um dos principais focos do ensino-aprendizagem de LEC, na medida em que garante o caráter formador do processo. Esta proposta de ensino de línguas por meio de práticas sócio-culturamente organizadas (gêneros), permite-nos, ainda, trabalhar a relação entre culturas locais e globais (Geertz, 1997) na aula de LEC.

Alinhando a visão enunciativa da linguagem ao pensamento de Bazerman (2005), Rocha (2006a, 2006b) procura relacionar as práticas sociais constitutivas do mundo infantil ao ensino de LEC. Nessa perspectiva, a autora propõe que o processo oriente-se por um sistema de atividades que envolvam gêneros que fazem contar, cantar e brincar, os quais se encontram interpolados, permitindo a construção de inúmeras possibilidades de interação. Nesse contexto, as práticas sociais desenvolvidas no ensino de LEC são orientadas por canções, festas ou brincadeiras populares, bem como narrativas em verso ou prosa, que envolvam personagens do folclore e dos contos infantis, dentre tantas outras possibilidades, as quais se fazem presentes nas mais diversas culturas que constituem nosso país e as demais nações do mundo, permitindo-nos explorar o plurilingüismo e a multiculturalidade de forma crítica (Kubota, 2004, entre outros) e, assim, emancipatória.

\section{Considerações finais}

Buscamos, através deste trabalho, tecer considerações acerca do processo de ensino-aprendizagem de LEC, a fim de possibilitar a reflexão sobre alguns, dentre os inúmeros fatores que influenciam o mesmo. Dentre os tópicos aqui brevemente discutidos, julgamos ser a formação do professor de LEC, o papel formativo desse ensino e a inclusão obrigatória do mesmo nas séries iniciais do Ensino Fundamental (Público), questões que merecem ser emergencialmente abordadas. Esses temas envolvem, conforme apresentado, o aspecto da exclusão social e o compromisso com a formação de indivíduos que sejam capazes de atuar em um mundo plural, de forma plena, por meio do ensino da LE.

A busca por um ensino mais efetivo no contexto em questão, através de interações propositadas, situadas e adequadas ao desenvolvimento da criança e aos propósitos estabelecidos a esse ensino, abarca o princípio de 
que a criança brasileira tem o direito a uma educação que a torne cidadã do mundo. Defendemos fortemente que as crianças são o futuro de nossa nação e que devemos, também pelo ensino de línguas, incentivá-las a acreditar em si mesmas, a valorizar seus interesses e a liderar caminhos. $\mathrm{Na}$ qualidade de profissionais da linguagem e educadores, entendemos ser de nossa responsabilidade, também, auxiliá-las a fortalecer sua identidade e a construir uma realidade sempre melhor, de forma responsável e digna. Finalmente, acreditamos que tornar tais objetivos realidade, se atrelados à luta contínua por políticas públicas que visem a uma sociedade mais justa e igualitária, encontra-se em nossas mãos.

Recebido em agosto de 2005

Aprovado em março de 2007

E-mail: claudiarocha@hotmail.com

\section{REFERÊNCIAS BIBLIOGRÁFICAS}

Abreu e Lima, Denise Martins.1996. O Processo de aquisição de língua estrangeira por crianças brasileiras em sala de aula: reflexões sobre a teoria de Krashen. Dissertação de Mestrado. Araraquara, Unesp. claudiahrocha@hotmail.com.

Almeida Filho, J.C. P. 1993. Dimensões comunicativas no ensino de línguas. Campinas: Pontes.

. (org.). 1999. O Professor de Língua Estrangeira em Formação. Campinas: Pontes.

. 2005. Lingüística Aplicada, Ensino de Línguas e Comunicação. Campinas: Pontes.

Almeida Filho, J.C. P. \& R. C. Barbirato. 2000. Ambientes comunicativos para aprender língua estrangeira. Trabalbos em Lingüística Aplicada. 36: 23-42.

Amaral, N. F. 2001. O ensino de línguas estrangeiras na formação integral das crianças: Abordagem Antroposófica. In: V. J. Leffa (org). O Professor de Linguas: Construindo a Profissão. Pelotas: Educat.

Assis-Peterson, A. A. \& M. O. C. GonçAlves. 2000/2001. Qual é a melhor idade para aprender Línguas? Mitos e Fatos. Contexturas- Ensino Crítico de Lingua Inglesa. 5: 11-27. 
Bakhtin, M. 2003 [1979]. Estética da Criação Verbal. São Paulo: Martins Fontes.

. 2004 [1929]. Marxismo e Filosofia da Linguagem. São Paulo: Hucitec.

BAKer, C. 1993. Foundations of Bilingual Education and Bilingualism. Clevedon: Multilingual Matters.

Baquero, R. 1998. Vygotsky e a Aprendizagem escolar. Porto Alegre: Artmed Editora.

Barbara, L. \& R. C. G. Ramos. (Orgs.).2003. Reflexão e Ações no Ensinoaprendizagem de Linguas. Campinas: Mercado de Letras.

Barbirato, R. C. 2005. Tarefas gerativas de insumo e qualidade interativa na construção do processo de aprender língua estrangeira em contexto inicial adverso. Tese de doutorado. Campinas, IEL/Unicamp.

Barbosa, J. P.2001. Trabalbo com Gêneros de Discurso: Uma Perspectiva para o Ensino de Lingua Portuguesa. Dissertação de Mestrado.São Paulo, LAEL/ PUC-SP.

Basso, E. A. 2001. A Construção Social das Competências Necessárias ao professor de Lingua Estrangeira: Entre o Real e o Ideal, Um Curso de Letras em Estudo. Tese de Doutorado. Campinas, IEL/Unicamp.

BLoor, M. 1995. The role of informal interaction in teaching English to young learners. In: C. Brumfit; J. Moon. \& R. Tongue (Eds.). Teaching English to Children: from practice to principle. Harlow: Longman.

Boneti, L.W. 1997. Educação, Exclusão e Cidadania. Ijuí: Editora Unijuí.

Brewster, J. 1995. What is good Primary Practice? In: C. Brumfit; J. Moon \& R. Tongue (Eds.). Teaching English to Children: from practice to principle. Harlow: Longman.

Brewster, J.; G. Ellis \& D. Girard. 2002. The Primary English Teacher's Guid- New Edition. London: Penguin.

BRITO, I. A. 1999. Conceitos de cultura e competência: contribuições para um ensino crítico de inglês no contexto brasileiro. Dissertação de Mestrado. Campinas, IEL/Unicamp.

Brown, D.2001. Teaching by Principles. New York: Pearson Education.

BRumfit, C. 1995. Intruduction: Teaching English to Children. In: C. BRumfit; J. Moon \& R. Tongue (Eds.). Teaching English to Children: from practice to principle. Harlow: Longman.

Bruner, J. S. 1960. The Process of Education. Cambridge: Harvard University Press.

. 1975. The ontogenesis of the speech act. Journal of Child Language. 3: 1-19, 1975. 
. 1986. The Culture of Education. Cambridge: Harvard University Press.

Bygate, M.; P. Skehan \& M. Swain (Eds.). 2001. Researching Pedagogic Tasks, Second language learning, Teaching and Testing. Harlow: Longman.

Byram, M. \& P. Doyé. 1999. Intercultural Competence and Foreign Language Learning in the Primary School. In: P. Driscoll \& P. Frost. Teaching of Modern Foreign Languages in the Primary Schools. Routledge.

Cameron, L. 2001. Teaching English to Young Learners. Cambridge: Cambridge University Press.

. 2003. Challenges for ELT from the expansion in teaching children. ELT Journal. 57/2: 05-112.

Canale, M. \& M. Swain. 1980. Theoretical Bases of Communicative Approaches to Second Language Teaching and Testing. Applied Linguistics. 1/1:1-48.

Cardoso, R. C. T. 1996. Jogar para Aprender Lingua Estrangeira na Escola. Dissertação de Mestrado. Campinas, IEL/Unicamp.

Celani, M. A. A.1997. Ensino de Segunda Lingua: redescobrindo as origens. São Paulo: EDUC. . 2003. Um Programa de Formação Contínua. In: M. A. A. Celani. (Org.). Professores e Formadores em Mudança: Relato de um Processo de Reflexão e Transformação da prática Docente. Campinas: Mercado de Letras.

Cook, G. 1997. Language Play, language learning. ELT Journal. 51/3: 224- 231.

Cox, M. I. P. \& A. A. de Assis-Peterson. 2007. Transculturalidade e Transglossia: Para Compreender o Fenômeno das Fricções LingüísticoCulturais em Sociedades Contemporâneas sem Nostalgia. In: M. C. Cavalcanti \& S. M. Bortoni-Ricardo. (Orgs.). Trasnculturalidade, Linguagem e Educação. Campinas: Mercado de Letras.

Cristovão, V. L. L. 2005. A Implicação da Constituição de Objetivos para o Ensino de Línguas Estrangeiras. In: M. P. Gimenez (Org.). Contribuições na Área de línguas estrangeiras. Londrina: Moriá.

Dolz, J. \& B. Schneuwly. 1996. Apprendre à écrire ou comment étudier la construction des capacities langagières? Éstudes de Linguistique Apliquée, 102: 73-86.

ElLIS, G. 2004. Developing Intercultural Competence with Children in the English Language Class. Thresholds Disponível em http:// w.w.w.counterpoint-online.org/doclibrary/british_council/download/ 179/Thresholds-1-Gail-Ellis.pdf. Acesso em 18 de dezembro de 2004. 
ElLIs, R. 2003. Task-based Language Learning and Teaching. Oxford: Oxford University Press.

Fabrício, B. F. 1999. Interação e Construção do Conhecimento na Sala de Aula de Língua Estrangeira. Intercâmbio. VIII: 217-235.

Falluh, H. M. 1978. O Fator Idade e o Início do Aprendizado de uma Língua Estrangeira: Estado Atual das Pesquisas. Dissertação de Mestrado.São Paulo, LAEL/PUC-SP.

Figueira, C.D.S. 2002. Crianças Alfabetizadas Aprendendo Lingua Estrangeira. Dissertação de Mestrado. Brasília, UnB.

Freire, P. 1988. Pedagogia do Oprimido. Rio de Janeiro: Paz e Terra. - 1996. Educação como Prática da Liberdade. São Paulo: Paz e Terra.

. 2004. Pedagogia da Autonomia: Saberes Necessários à Prática Educativa. São Paulo: Paz e Terra.

Funushima, M. 2004. Research Notes on Primary Foreign Language Teaching: Age, Time and Aims. Disponível em http//library.twins.ac.jp/kiyou/ 2004 jinbun.P.D.F/mifuku.p.d.f. acesso em 10 de agosto de 2004.

GARDNER, R.C. 1985. Social Psychology and Language Learning: role of attitudes and motivation. London: Edward Arnold.

Geertz, C. 1997. O Saber Local: novos ensaios em antropologia interpretative. Petrópolis: Vozes.

Gill, S. \& M. CANKovÁ..2003. Intercultural Activities. Oxford Basics. Oxford: Oxford University Press.

Gimenez, T. (Org.). 2002. Trajetória na formação de professores de línguas. Londrina: Ed. UEL.

. (Org.).2003. Ensinando e Aprendendo Inglês na Universidade: Formação de professores em tempo de mudança. Londrina: ABRAPUI.

Gimenez, K. M. P (Org.). 2005. Contribuições na Área de línguas estrangeiras. Londrina: Moriá.

Grigoletto, M.2000. Representação, identidade e aprendizagem de língua estrangeira. Claritas. 6: 37-47.

Haliwell, S. 1992. Teaching English in the Primary Classroom: Harlow: Longman.

Hall, N.1995. Literacy as social experience. In: C. BRumfit; J. Moon \& R. Tongue (Eds.). Teaching English to Children: from practice to principle. Harlow: Longman.

Harmer, J.1991. The practice of English language teaching. New York: Longman. 
Hernández, F. 1998. Transgressão e mudança na educação: Os projetos de trabalho. Porto Alegre: Artmed.

Holderness, J. 1995. Activity-based teaching: approaches to topic-centred work. In: C. Brumfit; J. Moon \& R. Tongue (Eds.). Teaching English to Children: from practice to principle. Harlow: Longman.

Huizinga, J. 1990. Homo Ludens: o jogo como elemento da cultura. São Paulo: Ed. Perspectiva.

Ioannou-Gergiou, S. \& P. Pavlou. 2003. Assessing Young Learners. Oxford: Oxford University Press.

Johnstone, R. 1994. Teaching Modern Languages at Primary School: Approaches and Implications. Edinburgh: SCRE. . 2002. Addressing "The Age factor": Some Implications for Language Policy. Guide for the development of Language Education Policies in Europe: from Linguistic Diversity to Plurilingual Education. Reference Study. Council of Europe, Strasbourg.

KHAN, J. 1995. Using names in teaching English to young learners. In: C. Brumfit; J. Moon \& R. Tongue (Eds.). Teaching English to Children: from practice to principle. Harlow: Longman.

Kemmis, S.1987. Critical reflection. In: M. F. Widden \& I. ANDrews. (Orgs.). Staff development for school improvement: a focus on the teacher. Nova York: The Falmer Press.

Kincheloe, J. L. 1997. A Formação do Professor como Compromisso Político: Mapeando o Pós-Moderno. Porto Alegre: Artes Médicas.

Kramsch, C.1993. Context and Culture in Language Teaching. Oxford: Oxford University Press.

Kubota, R. 2004. Critical Multiculturalism and Second Language Education. In: B. Norton \& K. Toohey (Eds.). Critical Pedagogies and language Learning. Cambridge: Cambridge University Press.

LANTOLF, J. 2000(a). Second language learning as a mediated process. Language teaching. 33: 79-96.

Leffa, V. 1998/1999. O Ensino de Línguas estrangeiras no Contexto nacional. Contexturas. 5/4: 13-24.

LENNENBERG, E. 1967. Biological foundations of language. New York: Wiley and Sons.

Leontiev, A. 1983. El desarrollo del psiquism. Madrid: Akal.

Lewis, M. 1986. The English Verb. Hove: Language Teaching Publications.

Lewis, M. \& G. Bedson. 2000. Games for Children. Oxford: Oxford University Press. 
Luz, G. A. 2003. O Ensino de Inglês para Crianças: Uma Análise das Atividades em Sala de Aula. Dissertação de Mestrado. Goiânia, UFG.

Magalhães, M. C. (Org.). 2004. A Formação do Professor como um Profissional Crítico. São Paulo: Mercado de Letras.

Maher, T. M. 2007. Do Casulo ao Movimento: A Suspensão das Certezas na Educação Bilíngüe e Intercultural. In: Marilda C. C. \& S. M. Bortoni-Ricardo. (Orgs.). Trasnculturalidade, Linguagem e Educą̧ão. Campinas: Mercado de Letras.

Marcuschi, L. A. 2002. Gêneros Textuais: definição e Funcionalidade. In: Dionísio, A. P. Dionísio; A. R. Machado \& M. A. Bezerra. Gêneros Textuais e Ensino. Rio de Janeiro: Lucerna. . 2006. Gêneros Textuais: Configuração, dinamicidade e circulação. In: A. M. Karwoski; B. GaydeczKa \& K. S. Brito (Orgs.). Gêneros Textuais: Reflexões e Ensino. Rio de Janeiro: Lucerna.

Martin, C. 1995. Games and Fun Activities. London: CILT.

McKAY, S. L. 2002. Teaching English as an International Language. Oxford: Oxford University.

McKay, P. 2006. Assessing Young Learners. Cambridge: Cambridge University Press.

Mitchell, R. \& F. Myles. 2002. Second Language Learning Theories. London: Arnold.

Moita Lopes, L. P. 1986. Oficina de Lingüística Aplicada: a natureza social e educacional dos processos de ensinolaprendizagem de lingua.Campinas: Mercado de Letras. . 2005. Ensino de inglês como espaço de embates culturais e de políticas da diferença. In: T. Gimenez; C. M. Jordão \& V. Andreotti (Orgs). Perspectivas Educacionais e o Ensino de Inglês na Escola Pública. Pelotas: EDUCAT.

Moon, J. 2000. Children Learning English. Oxford: Macmillan Heinemann. Moura, E. V. X. 2005. O nível de robustez interacional e a interferência das abordagens de ensinar do professor e dos autores do livro didático e de aprender dos alunos em aulas de língua estrangeira para iniciantes. Tese de Doutorado. Campinas, IEL/Unicamp

Nunan, D. 1989. Designing Tasks for the Communicative Classroom. Cambridge: Cambridge University Press. . 1999. Does Younger $=$ Better?. Matters. TESOL.

Oliveira, E. 2003. Políticas de ensino de línguas estrangeiras em escolas públicas do estado de São Paulo. Dissertação de Mestrado. Campinas, IEL/ Unicamp. 
Paiva, V.L.M.O.2006. Autonomia e Complexidade. Linguagem E Ensino. 9/1: 77- 128.

Perrenoud, P. 2000. Dez Novas Competências para Ensinar. Porto Alegre: Artmed.

Phillips, S. 2003. Young Learners. Oxford.: Oxford University Press.

Phillips, D.; S. Burnwood \& H. Dunford. 2001. Projects with Young Learners. Oxford: Oxford University Press.

PIAGET, J.1972. The Principles of Genetic Epistemology. New York: International Universities Press.

Prabhu, N. S.1987. Second Language Pedagogy. Oxford: Oxford University Press.

RIXON, S. The Role of fun games activities in teaching young learners. In: C. Brumfit; J. Moon \& R. Tongue (Eds.). Teaching English to Children: from practice to principle. Harlow: Longman.

Rocha, C. H. 2006(a). Provisões para Ensinar LE no Ensino Fundamental de $1^{a}$ a $4^{a}$ Séries: dos Parâmetros Oficiais e Objetivos dos Agentes. Dissertação de Mestrado. Campinas, IEL/Unicamp.

. 2006(b). O Ensino de LE (Inglês) para Crianças por meio de Gêneros: Um Caminho a Seguir. Contexturas: Ensino Crítico da Lingua Inglesa. 10: 65-93.

Rojo, R. 2005. Gêneros do discurso e gêneros textuais: questões teóricas e aplicadas. In: A. Bonini; J. L. Meurer \& D. Motta-Roth. (Orgs.). Gêneros: teorias, métodos, debates. São Paulo: Parábola Editorial.

Rosa, M. A. 2003. A Relação entre Domínio da Lingua Inglesa e Empregabilidade no Imaginário Brasileiro em Tempos de Mundialização do Capital. Dissertação de Mestrado. Campinas, IEL/Unicamp. Campinas.

Sadalla, A. M. F. A; F. Bacchiegga; Pina, T. A. \& M. Wisnivesky. 2002. Psicologia, Licenciatura e Saberes Docentes: Identidade, Trajetória e Contribuições. In: Azzi, R.G. Azzi \& A. M. F. A. Sadalla. (Orgs.). Psicologia e Formação Docente: Desafios e Conversas. São Paulo: Casa do Psicólogo.

SCAFFARO, A. P. 2006. O uso da atividade de contar histórias como recurso na retenção de vocabulário novo na língua inglesa em fase pré-escolar. Dissertação de Mestrado. Universidade do Vale dos Sinos.

Schneuwly, B. 1998. Lê langage ecrit chez l'enfant: la production des texts informatifs et argumentatifs. Neuchâtel: Delachaux \& Niestlé.

. 2004. Gêneros e tipos de Discurso: Considerações Psicológicas e Ontogenéticas- In: B. Schneuwly; J. Dolz Dolz. \& Colaboradores. Gêneros Orais e Escritos na Escola,. Campinas: Mercado de Letras. 
SchÖn, D. A. 1983. The Reflective Practitioner. Nova York: Basic Books. . 1987. Educating the Reflective Practitioner. San Francisco: Jossey Bass Publishers.

Scott, W. A \& L. Ytreberg. 1990. Teaching English to Children. London: Longman.

Scovel, T. 1988. A. Time to Speak: A Psycholinguistic Inquiry into the Critical Period for Human Speech. Rowley: Newbury House/Harper \& Row.

Serrani, S. 2005. Discurso e Cultura na Aula de Lingua: Currículo-LeituraEscrita. Campinas: Pontes.

SiLva, A. 1997. Era uma vez... O Conto de Fadas no Ensino/Aprendizagem de Lingua Estrangeira: O Gênero como Instrumento. Dissertação de Mestrado. São Paulo, LAEL/PUCSP.

Smith, J. 1992. Teacher's work and the politics of reflection. American Educational Research Journal. 29/2: 267-300.

Szundy, P. T. C. 2002. Os jogos no ensino-aprendizagem de LE para crianças: a construção do conhecimento através de jogos de linguagem. Intercâmbio: Uma Publicaşão de Pesquisas em Lingüística Aplicada. XI: $85-92$.

. 2005. A Construção do Conbecimento no Jogo e sobre o Jogo: EnsinoAprendizagem de LE e Formação reflexiva. Tese de Doutorado. São Paulo, LAEL/ PUCSP.

TAмBOs, H. H. F. 2006. Investigating language play in interaction: a qualitative study with children as foreign language learners. Dissertação de Mestrado. Florianópolis, UFSC.

Ticks, L. K. 2005. O livro didático sob a ótica do gênero. Linguagem $\mathcal{E}$ Ensino. 8/1:15-49.

Vale, D. \& A. Feuntein. 1995. Teaching Children English: A training Course for Teachers of English to Children. Cambridge: Cambridge University Press.

VAN LIER, L. 1996. Interaction in the Language Curriculum. Harlow: Longman.

VieIra-Abrahão, M. H. (Org.). 2004. Prática de Ensino de Lingua Estrangeira: experiências e reflexões. Campinas: Pontes Editores/Arte Língua.

Vygotsky, L. S. 1978. Mind in Society. Cambridge, M.A.: Harvard University Press.

. 1998 [1984]. A Formação Social da Mente. São Paulo: Martins Fontes. . 2001. A Construção do Pensamento e da Linguagem. São Paulo: Martins Fontes. 
W ALKER, S. 2003. Uma visão geral do ensino de inglês no Brasil. In: C.M.T Stevens \& M.J.C Cunha (Orgs.). Caminhos e Colbeita: ensino e pesquisa na área de inglês no Brasil. Brasília: Editora Universidade de Brasília.

White, R. 1988. The ELT Curriculum: Oxford: Basil Blackwell.

Widdowson, H. G. 1978. Teaching Language as Communication. Oxford: Oxford University Press.

Williams, M. \& M. Burden. 1997. Psychology for Language Teachers. Cambridge: Cambridge University Press.

Wood, D. 1998. How Children Think and Learn. London: Blackwell Publishing.

Wood, D.; J. Bruner \& G. Ross. 1976. The Role of Tutoring in Problem Solving. Journal of Child Psychology and Allied Disciplines. 17: 89-100.

Wright, A. 2001. Storytelling with Children. Oxford: Oxford University Press, 2001. . 2001. Art and Craft with Children. Oxford: Oxford University Press, 2001.

Zeichner, K. M. 1993. A Formação Reflexiva de Professores: idéias e práticas. Lisboa-Portugal: Educa. 